\title{
Mapping water vapour variability over a mountainous tropical island using InSAR and an atmospheric model for geodetic observations
}

Article

Accepted Version

Creative Commons: Attribution-Noncommercial-No Derivative Works 4.0

Webb, T. L., Wadge, G. and Pascal, K. (2020) Mapping water vapour variability over a mountainous tropical island using InSAR and an atmospheric model for geodetic observations. Remote Sensing of Environment, 237. 111560. ISSN 00344257 doi: https://doi.org/10.1016/j.rse.2019.111560 Available at https://centaur.reading.ac.uk/87723/

It is advisable to refer to the publisher's version if you intend to cite from the work. See Guidance on citing.

To link to this article DOI: http://dx.doi.org/10.1016/j.rse.2019.111560

Publisher: Elsevier

All outputs in CentAUR are protected by Intellectual Property Rights law, including copyright law. Copyright and IPR is retained by the creators or other copyright holders. Terms and conditions for use of this material are defined in the End User Agreement. 


\section{CentAUR}

Central Archive at the University of Reading

Reading's research outputs online 
1 Mapping water vapour variability over a mountainous tropical island using InSAR and an atmospheric model for geodetic observations

3

4 T. L. Webb ${ }^{1,2}$, G. Wadge ${ }^{1}$, K. Pascal ${ }^{3,4}$

1. Department of Meteorology, University of Reading, UK

2. Laboratoire d'Aérologie, Observatoire Midi-Pyrénées, Toulouse, France

3. Montserrat Volcano Observatory, Montserrat

4. Seismic Research Centre, University of the West Indies, Trinidad \& Tobago

Abstract

The three dimensional distribution of water vapour around mountainous terrain can be highly variable. This variability can in turn affect local meteorological processes and geodetic techniques to measure ground surface motion. We demonstrate this general problem with the specific issues of a small tropical island, Montserrat. Over a period of 17 days in December 2014 we made observations using InSAR and GPS techniques, together with concurrent atmospheric models using the WRF code. Comparative studies of water vapour distribution and its effect on refractivity were made at high spatial resolution $(300 \mathrm{~m})$ over short distances $(\sim 10$ $\mathrm{km}$ ). Our results show that model simulations of the observed differences in water vapour distribution using WRF is insufficiently accurate. We suggest that better use could be made of

24 the knowledge and observations of local water vapour conditions at different scales, specifically 25 the Inter Tropical Convergence Zone (ITCZ), the trade wind fields and the mountain flow $(\sim 30$ 
$26 \mathrm{~m})$ perhaps using eddy simulation. The annual perturbations of the ITCZ show that the range

27 of humidity is approximately the same expressed as the differential phase of InSAR imaging $28(\sim 100 \mathrm{~mm})$. Trade wind direction and speed are particularly important at high wind speeds 29 driving vigorous asymmetrical convection over the island's mountains. We also show that the 30 slant angles of radar can follow distinct separate paths through the water vapour field. Our study 31 is novel in demonstrating how synoptic-scale features and climate can advise the modelling of 32 mesoscale systems and sub-seasonal InSAR imaging on tropical islands.

33

34 Keywords: water vapour, mountainous tropical island, ITCZ, InSAR 


\section{Introduction}

Variation in the refractivity of the Earth's atmosphere can change the path and travel time of radiation passing through it. Making use of this behaviour contributes to boundary-layer meteorology (Stull, 1988), geodetic techniques such as Global Navigation Satellite Systems GNNS (Hofmann-Wellenhof et al., 1995) and synthetic aperture radar interferometry (InSAR) (Hanssen, 2001). Changes in refractivity are characterised by air temperature and pressure, particularly the partial pressure of water vapour (Bevis et al., 1994). Water vapour content generally increases downwards through the atmosphere and is most variable within the atmospheric boundary layer (ABL), a few kilometres thick and is the dominant reservoir of water vapour (Bengtsson, 2010).

Here we are mainly concerned with the varying refractivity of the atmosphere as it affects data collected by the InSAR method in which two phase images of the scene of interest are acquired at different times, but from very similar orbital positions, yielding coherent images of differential phase "delay". A common goal is to acquire the differential phase corresponding to land surface motion, having systematically removed or minimised the other "noise" effects (Hanssen, 2001). Of these effects, atmospheric water vapour variability has been the most difficult to remove. This is because of its rapid decorrelation over length scales of $\sim 100 \mathrm{~s}$ of $\mathrm{km}$ and time scales of $\sim 10$ s of days that are typical of Low Earth Orbit (LEO) radars used for most InSAR missions. Ways to mitigate the atmospheric noise have included independent observations of water vapour (e.g. GNSS, Li et al., 2005); the use of statistical time series methods with long datasets (e.g. Bekaert et al., 2015; Li et al., 2019) and models that simulate the atmosphere at the time of radar imaging. (e.g. Jolivet et al., 2011, 2014). The latter is the approach we use here, which is of considerable generality but difficult to apply in practice. For 

(

example, the initial conditions for the model are hard to generate, and convection is difficult to represent without using parameterizations. We do present other relevant data (e.g. GNSS and radiosonde), but do not attempt to combine them with atmospheric modelling to find an optimal joint solution. Montserrat is fortunate in having a dense network of GPS stations and a radiosonde site at a distance of $\sim 100 \mathrm{~km}$. We use these two sources to generate water vapour variability measurements to validate the numerical model- radar approach.

Conventionally for InSAR, the atmospheric contribution to the radar delay is considered to comprise four major components: Wet Delay (WD, due to water vapour), Liquid Water Delay (LWD), Hydrostatic Delay (HSD, due to atmospheric pressure) and Ionospheric Delay (due to electron density in the area of the atmosphere affected by solar radiation), (Hanssen, 2001). Recent studies (Feng et al., 2017) ; Fattahi et al., 2017), have shown that the ionospheric contribution can be significant for low frequency radars (e.g. L-band, $1.27 \mathrm{GHz}$ ) studying large length scales (several $100 \mathrm{~km}$ ). For our scale of study, the magnitude of ionospheric phase delay at a much higher frequency (X-band, $9.65 \mathrm{GHz})$ and a much smaller length scale $(\sim 10$ $\mathrm{km}$ ), are of much lower magnitude, allowing us to ignore that component. Hydrostatic delay variation can be significant at times of large surface pressure change (Tregoning and Herring, 2006), in areas of great topographic relief ( $\sim \mathrm{km}$, Elliott et al, 2008). We choose to ignore this effect in the case of Montserrat.

1 Differential InSAR, in which phase difference images are created from pairs of radar images separated in time, is sensitive to the changes in liquid water in clouds and particularly water vapour content along the radar path over this time period. Differential InSAR is an increasingly valuable tool for monitoring volcanoes (e.g. Lu and Dzurisin, 2014). Differential ground motions of a few mm can be detected and modelled in terms of pressurized magma storage and eruption processes (Pritchard et al., 2018; Ebmeier et al., 2018). However, many volcanoes 
have substantial edifices ( $>1 \mathrm{~km}$ high) such that the radar path to the base of the volcano has to pass through more water vapour than the equivalent path to the summit of the volcano. In this way the phase difference can be strongly modulated by topography. The resulting pattern of phase differences may be very similar to surface deformation generated by a pressure source centred within or below the edifice. This potential confusion of signals has been the subject of considerable study (e.g. Massonnet and Feigl, 1998; Wadge et al., 2002). This is particularly relevant for volcanoes that have high relief and which generate complex patterns of airflow associated with that relief. In these cases it is not just the topography that modulates the water vapour field but the dynamic flow of air over and around it. Here we address these processes using repeated InSAR measurements and numerical models of the delay due to atmospheric water vapour content.

The physical and temporal scales of the radar results and the steep island terrain provides a set of constraints distinct from equivalent continental scale studies $\left(\sim 10^{5}-10^{4} \mathrm{~km}^{2}\right)$, that tend to rely on the analysis of large radar datasets (e.g. Bekaert, et al., 2015, Alshawaf, et al., 2015). This in turn gives us the opportunity to better understand small-scale $\left(\sim 10^{3}-10^{2} \mathrm{~km}^{2}\right)$ processes involving the distribution of water vapour. Our investigation is set in the humid tropics. This has a distinctive climate driven by the Inter Tropical Convergence Zone (ITCZ) (Schneider et al., 2014), the Low-Level Jet (Munoz et al., 2008) and their interrelationship (Laderach and Raible, 2013) It is this combination of tropical climatology, diurnal boundary layer dynamics and localised, steep topography that is clearly important but little studied and forms the innovative basis of our study. Rather than relying on ever more difficult-to constrain initial conditions to the simulation of local delay fields, we propose that bringing to bear climatological data and insights will enable improved models to be created .We demonstrate this approach qualitatively in Fig. 1. 

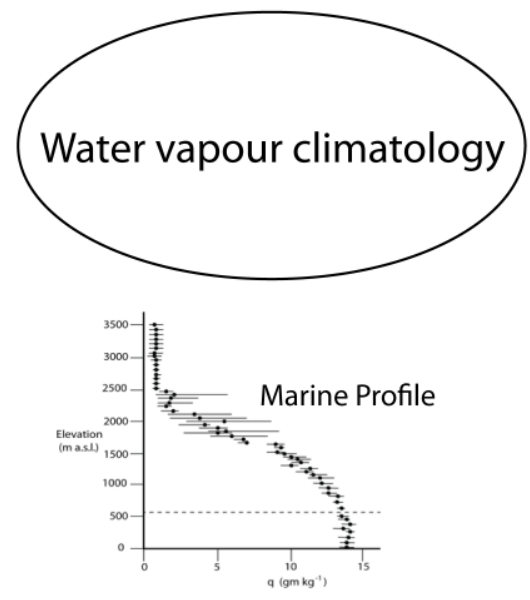

ITCZ : Annual Forcing

ZWD range $\sim 150 \mathrm{~mm}$

Trade Winds

Local Forcing of Flow $(\sim \mathrm{km})$

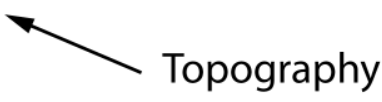

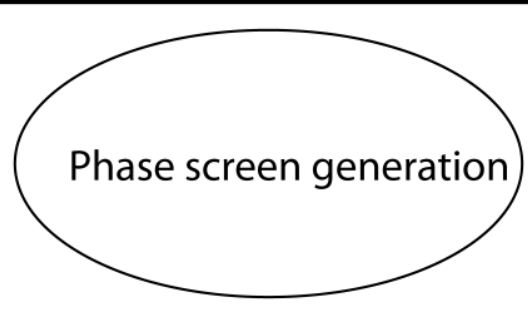

Differential InSAR

minimum $\sim$ days separation

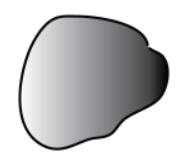

Topography Correction

Incidence Angle Correction

114 Fig.1 Schematic illustration of the potential use of water vapour climatology to mitigate the effects of tropospheric phase delay water vapour variability. On the right is a set of standard processing measures

116 in the use of differential InSAR, as used in this study. In contrast, on the left are three aspects of water

117 vapour climatology discussed in the text. Note that, apart from topography, there is no treatment that

118 links the two sets of measurements.

120 The objectives of this study are to:

1221.1 Understand where and when tropical water vapour originates.

1241.2 Measure and simulate the water vapour field over a small mountainous tropical volcano

125 using InSAR phase fields, equivalent atmospheric models and GNSS (and local field data)

126 during a 17-day campaign.

128 1.3 Show that the ambient state of the ITCZ, the trade winds and the radar viewing geometry

129 can play important roles in the variability of water vapour. 
131 These objectives provide the structural sub-headings used in the Discussion.

132

133

134
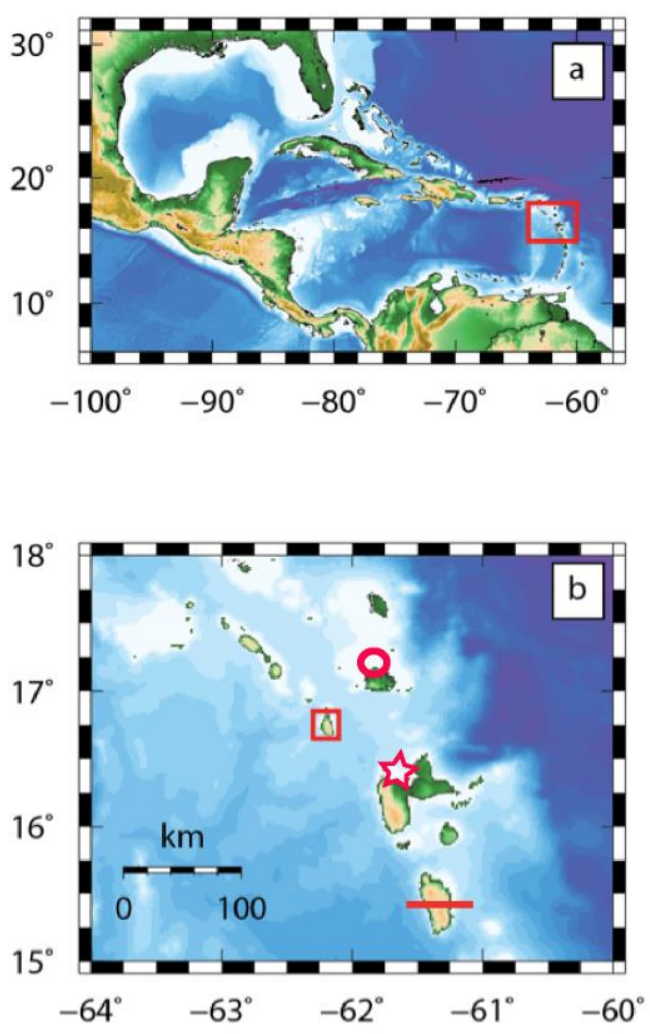

135

136

137

138

139

140

141

142

143

144

145

146

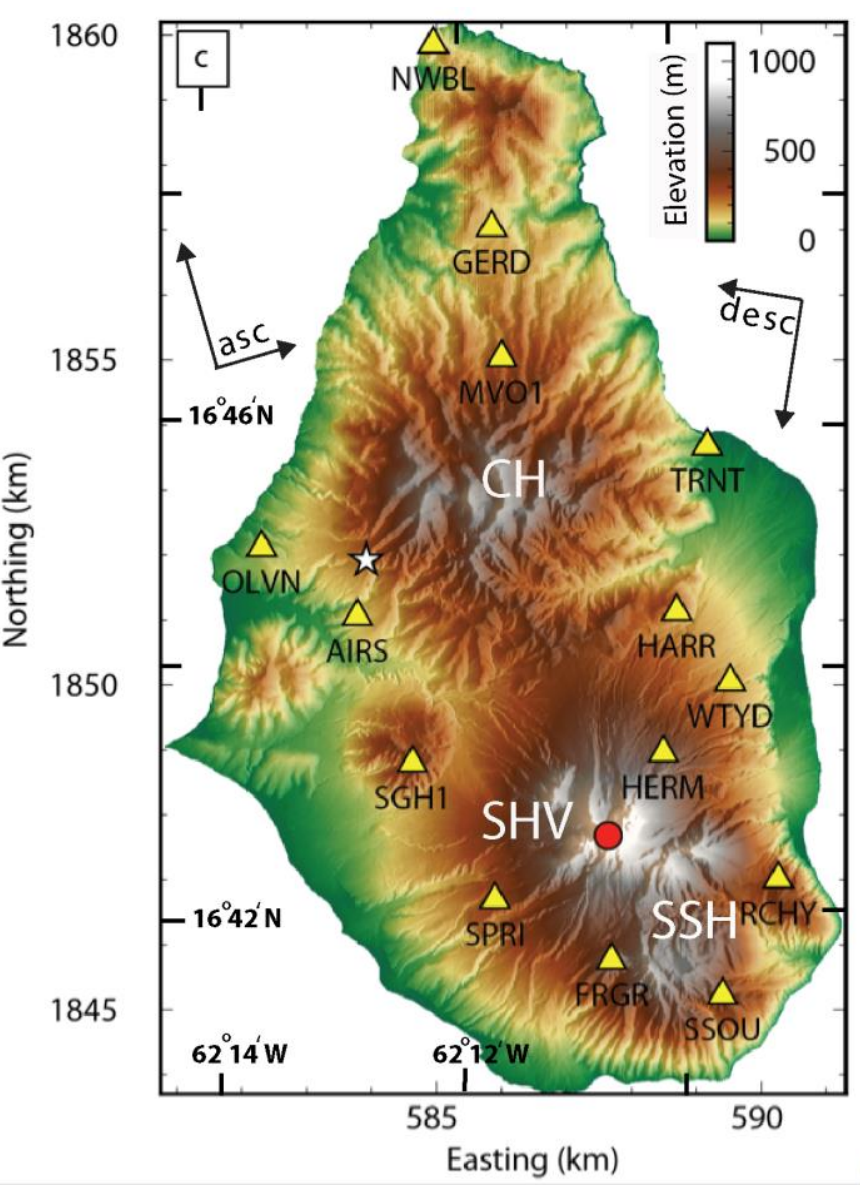

Fig.2 Location of Montserrat. (a) In the eastern Caribbean Sea (red box), (b) In the central Lesser Antilles, framed by a red box. The red circle denotes the location of Antigua (Fig.4), the red star represents Le Raiset, Guadeloupe where sondes are launched (Fig. 12), and the red line represents the transect across Dominica for the model results shown in Fig.8).(c) Shaded elevation map of Montserrat (McVicar and Korner, 2013) showing the locations and names of the continuous GPS stations (yellow triangles). The white star gives the position of the Montserrat Volcano Observatory and the red circle is the lava dome of the Soufrière Hills Volcano (SHV). CH is the location of the Centre Hills, SSH is the South Soufrière Hills. ASC shows the orientation of the ascending pass satellite track and incidence azimuth. DESC shows the same for the descending pass satellite track. The internal coordinates are latitude and longitude, the external coordinates are the local grid for Montserrat. 


\section{The Study Site: Montserrat, Lesser Antilles}

153 We base our study on Montserrat (Fig. 2), a small ( 10 x $16 \mathrm{~km})$ volcanic island in the Lesser 154 Antilles $\left(17^{\circ} \mathrm{N}, 62^{\circ} \mathrm{W}\right)$. The Soufrière Hills Volcano (SHV), whose summit is about $1083 \mathrm{~m}$ 155 above sea level (a.s.1), occupies the southern half of the island, and has been active since 1995, 156 causing the destruction of the capital city Plymouth and the emigration of more than half the 157 population (Fig.2c) (Wadge et al., 2014). Improved geodetic monitoring is important for the 158 mitigation of future volcanic risk in Montserrat (Odbert et al., 2014) and at other similar 159 volcanoes.

160 The Lesser Antilles islands sit in the eastern Caribbean Sea a region of atmospheric interactions 161 that determine the humidity, winds and rainfall experienced (Taylor and Alfaro, 2005). The 162 main mechanisms involve the Atlantic, or western, part of the Inter Tropical Convergence Zone 163 (ITCZ) and the North Atlantic Subtropical High (NASH) (Waliser and Gautier, 1993; Martinez 164 et al., 2019). The ITCZ is a global zone of clouds and storms together with the trade winds 165 blowing from the east and from the east southeast at different times of year (Richter et al., 166 2017). The NASH provides strongly divergent winds and atmospheric subsidence in the eastern 167 Caribbean atmosphere. As the ITCZ migrates northwards away from the equator in the boreal 168 summer, it reaches its most northerly position in June, July and August (JJA). Specific humidity 169 increases at the latitude of Montserrat, within a range of about $1-6 \mathrm{~g} / \mathrm{kg}$ (Fig.3). However, this 170 field is highly smoothed in Fig.3 and humidity varies strongly on a small scale in both space 171 and time (Bengtsson, 2010). 
172 The ITCZ is particularly important because the evaporation flanking the ITCZ forms the main

173 baseline source of humidity for the Lesser Antilles. Figure 3 shows the zonal mean distribution

174 of observed specific humidity and precipitation based on ERA-interim reanalysis data

175 (Laderach and Raible, 2013) for July, the pivotal point of the migration. The ITCZ migration

176 from the equator during JJA also involves the strengthening of the southeast trade winds at 177 ground level, from $3.2 \mathrm{~m} / \mathrm{s}$ in April to $5.4 \mathrm{~m} / \mathrm{s}$ in July (Richter et al., 2017).

178

179

180

181

182

183

184

185

186

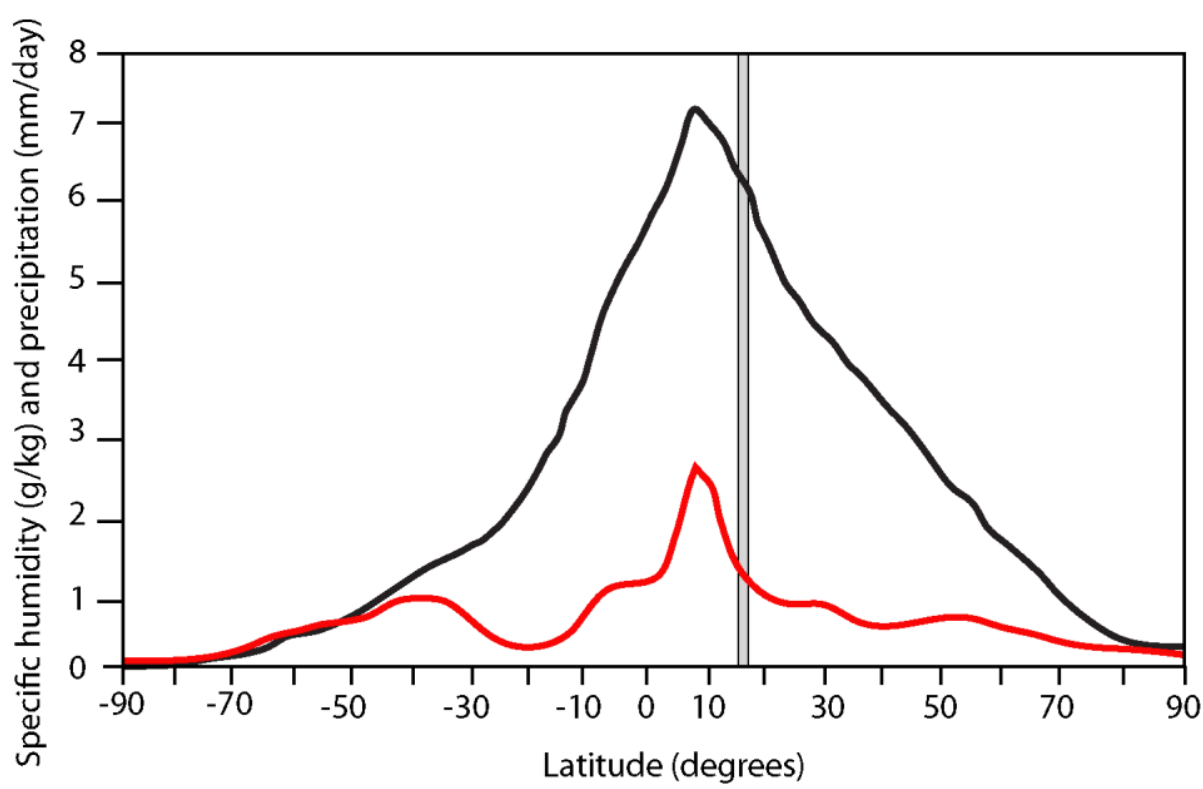

Fig.3 Latitudinal plot of the zonal mean distribution of observed specific humidity and precipitation of the ITCZ for July from 1979 to 2010. The black curve is from ERA-interim specific humidity data, the red curve is for precipitation. The grey rectangle covers the location of the study site (after Laderach and Raible, 2013).

Figure 4 shows the annual impact that the ITCZ has on rainfall in the Lesser Antilles, in this case in Antigua, to the northeast of Montserrat (Fig.2b). December to March is a dry season followed by rising rates of rain with an irregular peak in November, a pattern common to many islands in the Lesser Antilles. The difference in rainfall rate over the year due to the migration of the ITCZ in the Eastern Caribbean is about $5 \mathrm{~mm} /$ day (Fig.4). 


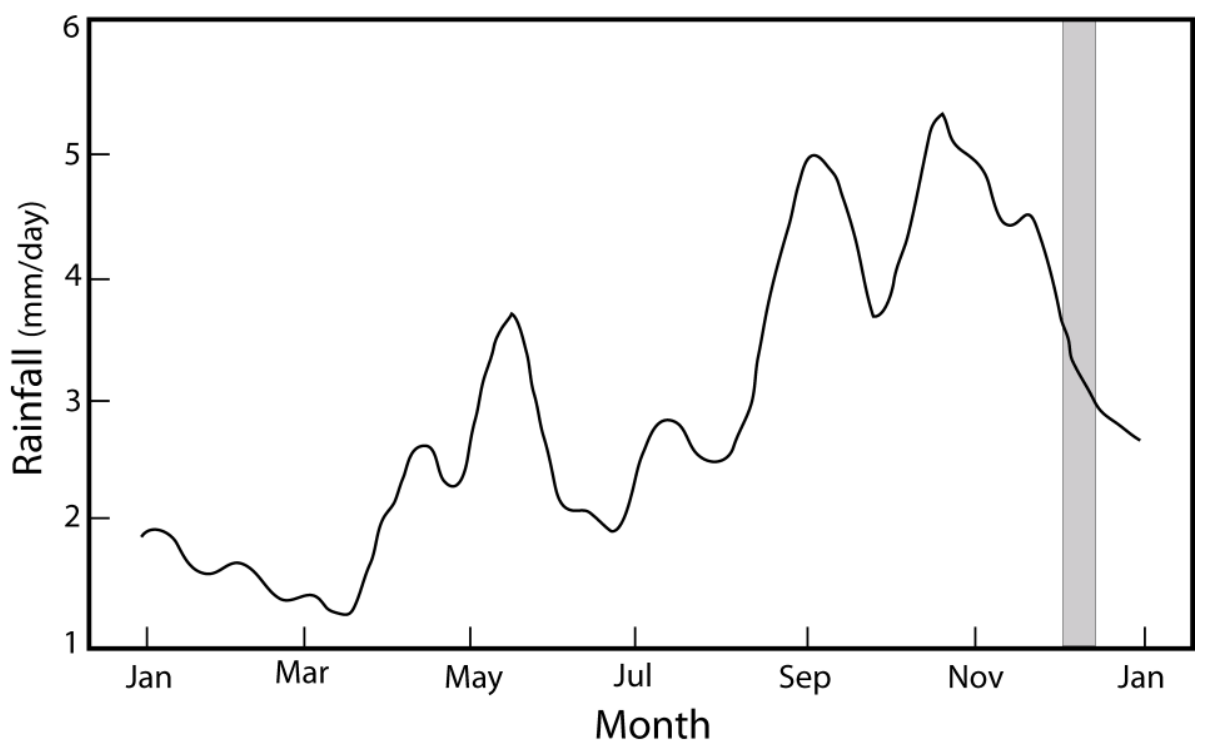

191 Fig.4 Rainfall climatology for 1969-2017 at Antigua, northeast of Montserrat. Values are average rainfall in $\mathrm{mm} /$ day (adapted from Martinez et al., 2019). The grey band is the period of radar data acquisition in December 2014 that is studied in detail.

Another significant feature of the tropical circulation are the low level jets (LLJs). These are regions of high winds in the lower troposphere coupled with an annual cycle of precipitation and a rainy season extending from May through October in the Caribbean (Munoz et al., 2008). There is a temporal maximum in wind speeds in July and a minimum in February (Fig.5). Spatial (zonal) wind speed maxima occur at a pressure of about $925 \mathrm{hPa}\left(\sim 700 \mathrm{~m}\right.$ above sea level) with speeds reaching maxima of $\sim 14 \mathrm{~ms}^{-1}$ in July and minima of $\sim 8 \mathrm{~ms}^{-1}$ in October (Fig.5). Diurnal wind speed variability tends to peak in the

morning. 


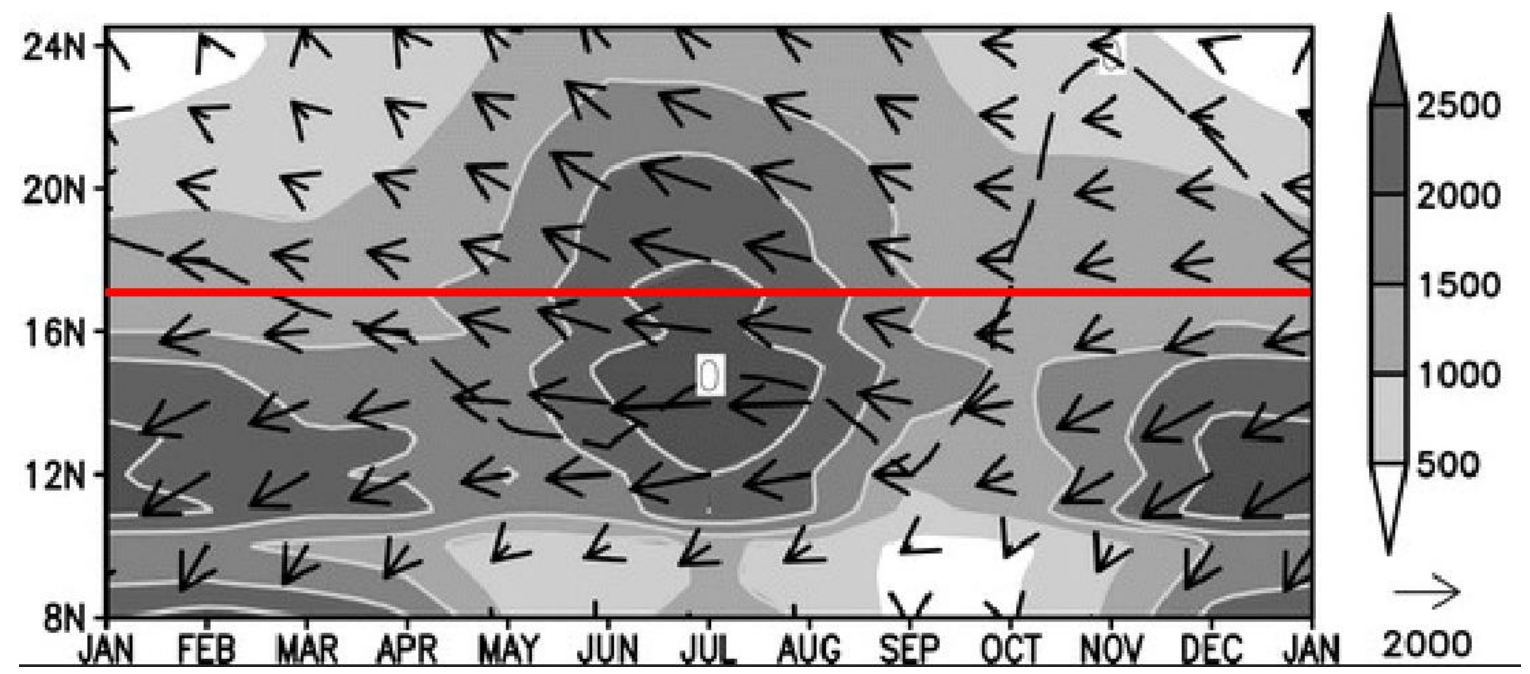

213 Fig. 5 The zonal moisture flux across the Caribbean plotted in latitudinal-monthly space. The grey

214 shading is of moisture flux and the arrows are moisture flux vectors generated from the North American

215 Regional Reanalysis (NARR, Munoz et al., 2006). Montserrat's location is represented by $17 N$ latitude

216 (solid red line)and by December.. The moisture flux decreases about a peak value in July of $2500 \mathrm{~g} \mathrm{~kg}^{-}$

$217{ }^{1} m s^{-1}$ to about half that between October and April.

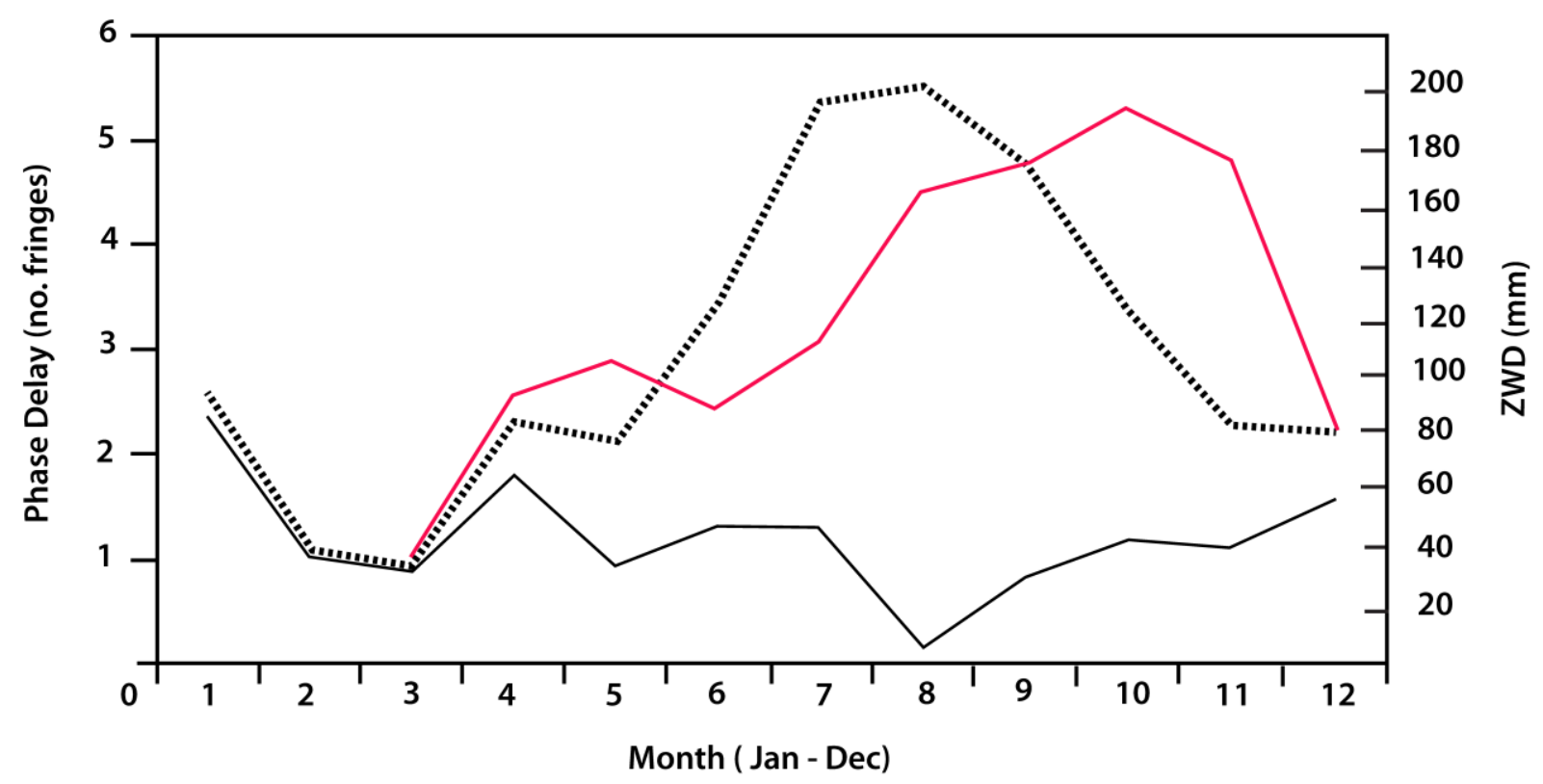

219 Fig.6 Plot of monthly mean phase delays at Fogo volcano between June 2005 and December 2007

220 (Black dashed line gives the number of delay fringes, black continuous line gives the standard deviation)

221 (adapted from Heleno et al., 2010). Red line gives an equivalent plot of monthly phase ZWD delays

222 averaged from March 1998 to November 2000 at SHV volcano on Montserrat (taken from Wadge et al.,

223 2006). 
224 In the eastern Atlantic part of the ITCZ, the Fogo Volcano shows a similar behaviour to that at 225 SHV, Montserrat (Heleno et al., 2010). Using a 2.5 year-long dataset of 71 ASAR radar images 226 Heleno et al. were able to show strong seasonal signals of humidity and resulting phase delay 227 (Fig.6). The amplitude of the ITCZ-derived annual variability of water vapour at Fogo was 228 measured at up to $17 \mathrm{~cm}$ of equivalent ground motion between sea level and about $2000 \mathrm{~m}$ a.s.l.

229 (Fig.6). This agrees with independent MODIS-derived, precipitable water vapour (PWV) 230 values. Montserrat has a similar annual relationship to Fogo in this regard. Fig.6 shows the 231 monthly ZWD variation values over a 2.5-year period. Whilst the SHV and Fogo have slightly 232 different peaks in their water vapour contents the broad pattern of dominant water vapour 233 content in the winter is obvious. Effectively, much of the seasonal water vapour signal 234 variability is generated by the ITCZ migration. From the perspective of InSAR geodetic 235 monitoring, the variability of differential phase will tend to be much greater if the 236 interferometric pair comprises data from, say, May and November, rather than from January to 237 April (Fig.6).

238 The strength and timing of the ITCZ varies from season to season and from one year to the 239 next. For example, the wind direction data collected by Wadge et al., (2006) on Montserrat 240 between 1998 and 2000 (Table 5) shows monotonous easterly winds in April and highly 241 variable winds in July.

243 In addition to the ITCZ, weather systems at the 100-1000 km scale affect Montserrat. These 244 include cyclonic systems, up to hurricane strength, carried westward across the Atlantic as 245 "easterly waves" during the wet season, together with locally originating large convective 246 systems (Matthews et al., 2002; Barclay et al., 2006). Troughs of dry upper tropospheric air 247 also occur in the eastern Caribbean (e.g. Wadge et al., 2016). From our perspective the most 248 significant impact that these events have is their disruption of the ABL, particularly the speed 249 and direction of the wind over the island. 
The ABL over the sea surrounding Montserrat is relatively simple compared to that over the

251 islands. The Atlantic Ocean ABL upwind from Montserrat was studied by the Barbados 252 Oceanographic Meteorological Experiment (BOMEX), (Siebsma et al., 2003) and the Rain in 253 Cumulus Over the Ocean (RICO), (Davison et al., 2013) field measurement campaigns. 254 Typically, cumulus cloud develops over the sea during the day, usually below a temperature 255 inversion. These clouds and other sub-cloud, high-moisture content air parcels act as triggers 256 for buoyant convection when advected over land (Kirshbaum and Smith, 2009) resulting in 257 taller and broader cumulus clouds over the islands. The water vapour field over the open ocean, 258 measured in the RICO study, typically takes the form of the profile shown in Fig.7 (Stevens, 259 2006). Below the lifting condensation level (LCL) the water vapour specific humidity is fairly 260 constant and reaches the highest values. Above it, within the cloud layer, the mean specific 261 humidity decreases strongly with altitude but its variability increases (Fig.7). Above the 262 cumulus layer the humidity often has a low, uniform value. Typically, the ABL has a thickness 263 of about $2 \mathrm{~km}$ but it can be up to $4 \mathrm{~km}$ in the winter months (Davison et al., 2013). Radiosonde264 derived specific humidity profiles for the days of radar imaging are discussed in section 5.1. A 265 strong diurnal cycle of water vapour variability was observed on 4-5 August, 2013 in the ground 266 radar interferometer measurements of Wadge et al. (2016) over Montserrat. The windward 267 slopes of the mountains were heated first at sunrise and a rapidly mixing layer driven by 268 convective heating developed over about 2 hours. This reached its maximum development in 269 the early afternoon. After sunset the ABL rapidly evolved to a much weaker mixed layer above 270 a lowermost stable layer, with greatly reduced variance in water vapour.

272 The trade winds in the Lesser Antilles mainly blow from east northeast. The relatively uniform 273 marine ABL changes its structure due to the interaction with topography and the daytime 274 heating of the islands' surfaces. The trade winds blow roughly perpendicular to the topographic 
axes of the islands in the northern and central part of the arc such as at Montserrat, giving

276 asymmetrical windward and leeward characteristics. The

277 speed and direction of the trade winds play important roles in the development of clouds,

278 precipitation and topographic flows. The atmospheric processes over some of the islands of the

279 Lesser Antilles have been studied intensively in recent years. These include: cloud trails

280 forming due

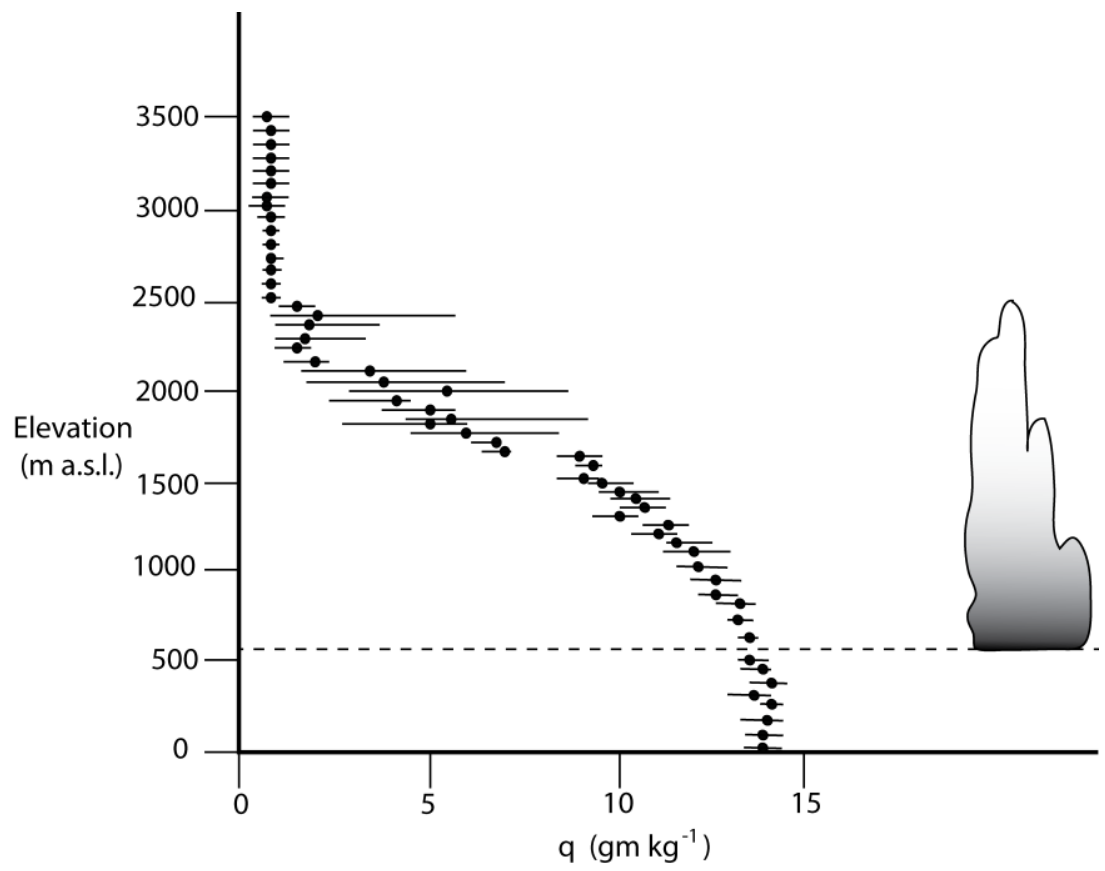

284 Fig.7 Profile of water vapour specific humidity $(q)$ values measured during the $10^{\text {th }}$ research flight of 285 the RICO campaign (Stevens, 2006). Above the LCL (dashed line, 600 m a.s.l.) mean values of $q$ (black 286 dots) decrease up to the top of the cumulus layer at about $2200 \mathrm{~m}$ a.s.l. (shown schematically on the right), whilst the variability increases (black lines are the interquartile ranges).

to diurnal heating (Smith et al., 1997; Kirshbaum and Fairman, 2015), island-induced winds, 290 including katabatic flow (Cécé et al., 2014), orographic precipitation (Kirshbaum and Durran, 291 2004; Kirshbaum and Smith, 2009; Smith et al., 2012), orographic convection (Minder et al., 
292 2013; Nugent et al., 2014; Wang and Kirshbaum, 2015) and volcanically-triggered rainfall 293 (Poulidis et al., 2016).

294 Dominica (200 km to the southeast of Montserrat) experiences similar trade wind weather to 295 Montserrat, and as shown in Fig.8a. For low wind speeds $(<5 \mathrm{~m} / \mathrm{s})$ diurnal thermal convection 296 dominates (Smith et al., 2012), and the eastern (windward) side of the island in the case of low 297 wind speeds from the north, the eastern side of the island has a much more complex humidity 298 field than the western (lee)side. For high wind speeds ( $>7 \mathrm{~m} / \mathrm{s}$, Fig.8b) mechanically driven 299 convection occurs, most strongly over the eastern windward slopes, and the form of the 300 resultant water vapour field is reversed, with drier air above the leeward slopes. On Dominica, 301 Minder et al. (2013) showed that at high wind speeds $(\sim 12 \mathrm{~m} / \mathrm{s})$, plunging flow on the leeward 302 (western) slopes of the mountain reduces the specific humidity, at altitudes below about 1-1.5 $303 \mathrm{~km}$ a.s.l. and around the summit, by up to $3-4 \mathrm{~g} / \mathrm{kg}$ relative to values on the windward (eastern) 304 side. 

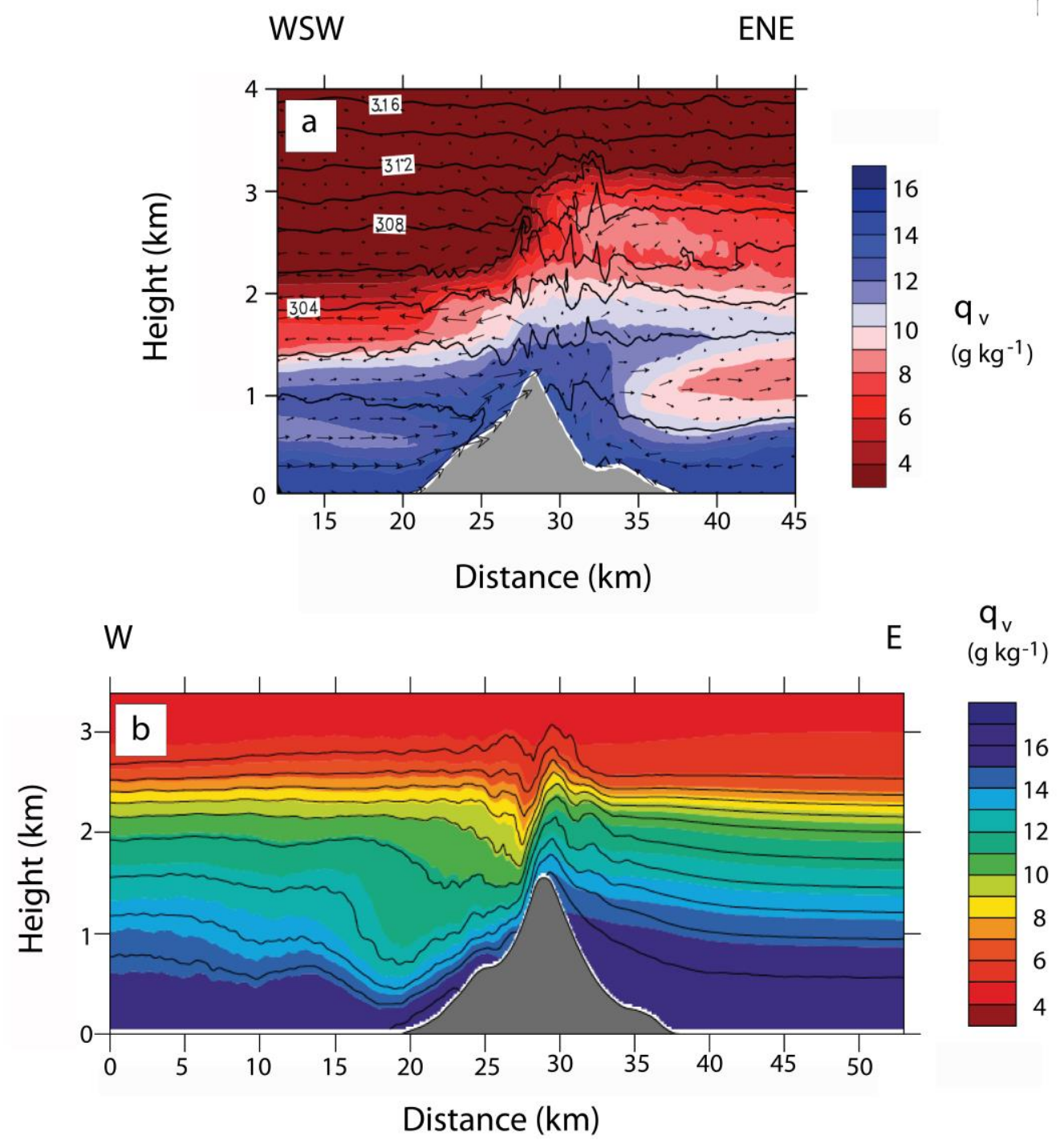

308 Fig.8 Transects of modelled specific humidity fields from Dominica whose locations are 309 approximately shown in Fig.2b. (a) Low wind speed WRF model with an ENE-WSW section output of a 310 4-hr averaged water vapour specific humidity field ( $q_{v}$, coloured) over Dominica. The wind direction is 311 shown by arrows and the speed is low, about $2 \mathrm{~m} / \mathrm{s}$, from the north. Potential temperatures are given by 312 the black lines. Data courtesy of D. Kirshbaum, from the study of Wang and Kirshbaum (2015). (b) High 313 wind speed WRF model with an E-W section output of 6-hr averaged water vapour specific humidity 314 field (coloured) over Dominica. The trade winds blow from the right (east-south-east) at a speed of 315 about $12 \mathrm{~m} / \mathrm{s}$ (from Minder et al., 2013).

317 Sometimes a train of lee waves will develop. Figure 9a shows an example of this captured by 318 MODIS imagery of Montserrat at 17:30 local time on $3^{\text {rd }}$ August 2013. A WMM image of 
integrated water vapour content for the same time (Fig.9b) simulates well the two strong waves

320 that developed to the lee side of the island. The lee waves have peak-to-trough amplitudes of 321 about $15 \mathrm{~mm}$ of ZWD.
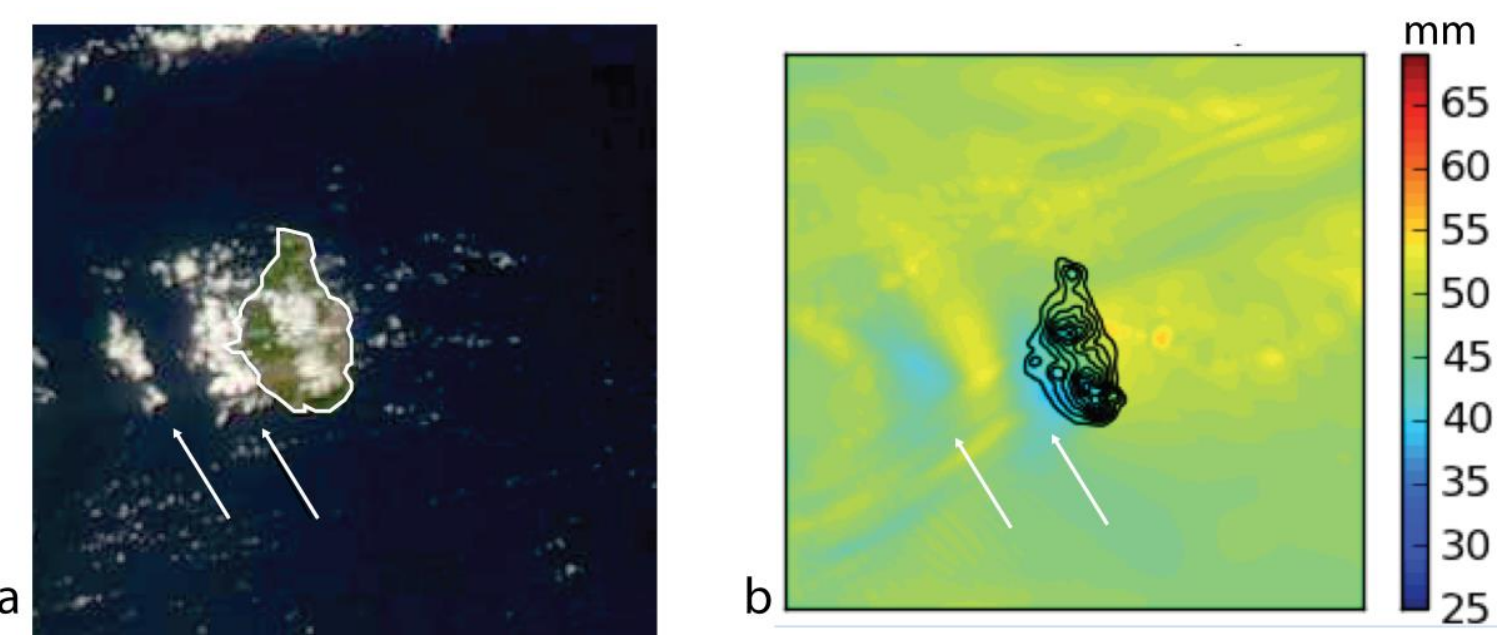

Fig. 9 Lee waves produced downwind of Montserrat during trade wind flow at 17:30 on $3^{\text {rd }}$ August 2013. (a) MODIS Terra image showing Montserrat (16 km N-S), outlined in white, covered in green vegetation and buff volcanic deposits. Three banks of cumulus cloud produced by lee waves (white arrows) are evident. (b) WMM simulation, at same time as (a), of the vertically integrated water vapour content. See Fig.S1 for GPS-ZWD calculation.

\section{Methods}

\subsection{InSAR}

333 A radar image of the ground surface, when compared to a geometrically equivalent image 334 acquired at another time can give a coherent measure of the phase change during that interval. 335 This is the principle of InSAR and, as in our case, the interferograms are acquired every few 336 days by radar-hosting satellites in sun-synchronous dawn-dusk orbits (Hanssen, 2011), using 337 GAMMA software. We requested from the Italian Space Agency (ASI) an intensive observation campaign using the COSMO-SkyMed constellation of four X-band radars between 

on the ground in Montserrat during the satellite imaging. The measured phase in the

341 interferograms is the combined sum of components derived from the orbit (Fattahi and 342 Amelung, 2014), the viewing geometry (Goldstein and Werner, 1998), the topography (Spaans 343 and Hooper, 2016), the motion of the ground, the refractive delay of the atmosphere (Li et al., 344 2019), the nature of the surface scattering and noise (Zebker and Villasenor, 1992). In our case 345 we can explicitly correct for the geometry from knowledge of the satellites' orbits and for the 346 topography by using a 25m-DEM. GPS measurements made by MVO, show that there was no 347 significant ground deformation during our survey (Stinton et al., 2016). The residual signal 348 should be that due to the change in refractivity and noise, including uncompensated ground 349 surface change.

Table 1. COSMO-SkyMed imaging times and angles

\begin{tabular}{|l|l|l|l|l|l|}
\hline Date & Pass & $\begin{array}{l}\text { Image Time } \\
(\text { local time })^{3}\end{array}$ & $\begin{array}{l}\text { Sunrise/Sunset } \\
(\text { local time })\end{array}$ & $\begin{array}{l}\text { Incidence Angle }^{1} \\
\left({ }^{\circ}\right)\end{array}$ & Azimuth Angle $^{2}$ \\
\hline 2/Dec/2014 & asc & $05: 58$ & $06: 20$ & 26.6 & 069 \\
\hline $3 /$ Dec/2014 & asc & $05: 58$ & $06: 21$ & 26.6 & 069 \\
\hline 6/Dec/2014 & des & $17: 34$ & 17.35 & 59.2 & 281 \\
\hline 10/Dec/2014 & des & $17: 34$ & $17: 37$ & 59.2 & 281 \\
\hline 14/Dec/2014 & des & $17: 34$ & $17: 38$ & 59.2 & 281 \\
\hline 18/Dec1/2014 & asc & $05: 58$ & $06: 29$ & 26.6 & 069 \\
\hline 19/Dec/2014 & asc & $05: 58$ & $06: 30$ & 26.6 & 069 \\
\hline
\end{tabular}

352 1. Angle from vertical of radar impinging on surface.

353 2. Direction of look of radar in the horizontal plane $\left(0-360^{\circ} \mathrm{N}=0\right.$, clockwise $)$.

354 3. Local time is UTC - $4 \mathrm{hr}$. 
Table 2. Meteorological conditions at radar overpass

\begin{tabular}{|l|c|l|l|l|l|l|}
\hline Date & $\begin{array}{c}\mathrm{T} \\
\left({ }^{\circ} \mathrm{C}\right)\end{array}$ & $\begin{array}{l}\mathrm{RH} \\
(\%)\end{array}$ & $\begin{array}{l}\text { WV Lapse } \\
\mathrm{Mm} / \mathrm{m}\end{array}$ & $\begin{array}{l}\text { Wind } \mathrm{RS}^{1} \\
\left({ }^{\circ}\right) / \mathrm{m} / \mathrm{s}\end{array}$ & $\begin{array}{l}\text { Wind } \mathrm{G}^{2} \\
\left({ }^{\circ}\right) / \mathrm{m} / \mathrm{s}\end{array}$ & $\begin{array}{l}\text { Wind } \mathrm{TR}^{3} \\
\left({ }^{\circ}\right) / \mathrm{m} / \mathrm{s}\end{array}$ \\
\hline $2 / \mathrm{Dec} / 2014$ & 24 & 89 & 0.075 & $087 / 5$ & $070 / 2$ & $175 / 1$ \\
\hline $3 / \mathrm{Dec} / 2014$ & 24 & 89 & 0.107 & $040 / 3$ & $030 / 11$ & $140 / 2$ \\
\hline $6 / \mathrm{Dec} / 2014^{4}$ & 23 & 90 & 0.097 & $258 / 5$ & $330 / 7$ & $190 / 2$ \\
\hline $10 / \mathrm{Dec} / 2014^{5}$ & 25 & 80 & 0.098 & $148 / 6$ & $170 / 3$ & $100 / 2$ \\
\hline $14 / \mathrm{Dec} / 2014$ & 25 & 70 & 0.098 & $135 / 9$ & $170 / 3$ & $100 / 2$ \\
\hline $18 / \mathrm{Dec} / 2014$ & 23 & 83 & 0.095 & $009 / 1$ & $070 / 2$ & $000 / 2$ \\
\hline 19/Dec/2014 & 24 & 78 & 0.083 & $084 / 10$ & $110 / 6$ & - \\
\hline
\end{tabular}

359 1. Wind velocity measured by radiosonde above Guadeloupe $(<600 \mathrm{~m}$ asl).

360 2. Wind velocity measured by anemometer at Geralds airport.

3613 . Wind velocity measured at Tar River GPS site.

362 4. Mesoscale cumulus to southeast.

363 5. Cloud trails SSE to NNW (Kirshbaum and Fairman, 2015).

Table 1 gives details of the radar image acquisitions and table 2 gives the meteorological conditions at the times of acquisition.

367 Random changes in time in the location or strength of the local scatterers within a radar beam

368 will increase the phase noise. Surfaces covered by wind-blown trees or rapidly growing

369 vegetation can become incoherent, whilst the phase signal from a rocky or soil-covered surface may remain coherent. On Montserrat, the forests (at South Soufrière Hills and Centre Hills,

371 Fig.2c) become incoherent to X-band radar signals over a few hours. Because the phase 372 gathered by InSAR systems is modulo 2pi, the ambiguity this creates must be removed by 373 unwrapping of the phase signal. Here we use a minimum cost flow method (Costantini, 1998).

374 Areas with incoherent signal or poor unwrapping of phase are masked. The ascending and descending pass masks are different in detail, reflecting their viewing geometries, but largely 
comprise the areas of Centre Hills and South Soufriere Hills (Fig.2c), which were not denuded of forest cover during the 1995 - 2010 eruption.

\subsection{Atmospheric Models}

380 The small size of Montserrat requires a high-resolution model to represent both the topography

381 and its impact on airflow over and around it. The model used is the WRF Montserrat Model 382 (WMM) and a detailed description of the WMM can be found in Webb (2015). Céce et al., 383 (2014) used a similar, though coarser, WRF-based model to represent Guadeloupe. The WMM uses the European Centre for Medium-range Weather Forecasting, (ECMWF) operational forecast data on a $16 \mathrm{~km}$ grid truncated onto a horizontal $19 \mathrm{~km}$ grid level as its initial condition, and simulations are successively nested through domains with $8.1 \mathrm{~km}, 2.7 \mathrm{~km}, 0.9 \mathrm{~km}$ and 0.3 $\mathrm{km}$ grids. The lower domain boundary is a $30 \mathrm{~s}$ regional terrain dataset imposed on all nested grids, except the $0.3 \mathrm{~km}$ grid, whose surface is represented by a bespoke mapping of the cover of Montserrat by water, farmland, forest and bare rock. The topography is represented by a 25 $\mathrm{m}$ horizontal resolution DEM. Table 3 shows the parameterizations used in the WMM at each domain level. In the vertical, the grid comprised 51 eta levels (using a terrain-following hydrostatic pressure coordinate) skewed to the lower troposphere - the lowest region of the atmosphere. A few closely packed layers near the upper domain boundary (20 km) were used to control wave reflections. Adaptive time stepping was used (see table 3 ) and controlled by the stability of the Courant-Friedrichs-Lewy condition on the innermost domain. The model spinup time was 10 hours. 
Table 3. $\quad$ Parameterisation options for WMM in each spatial domain

\begin{tabular}{|c|c|c|c|c|}
\hline & Domain 1 & Domain 2 & Domain 3 & Domain 4 \\
\hline Resolution (km) & 8.1 & 2.7 & 0.9 & 0.3 \\
\hline Starting $\mathrm{Ts}^{-1}$ & 10 & 8 & 6 & 4 \\
\hline i start offset ${ }^{2}$ & 1 & 65 & 65 & 52 \\
\hline j start offset ${ }^{3}$ & 1 & 65 & 62 & 62 \\
\hline Cumulus & Grell Devenyi & Grell Devenyi & None $^{4}$ & None $^{4}$ \\
\hline
\end{tabular}

For each of the following parameters the values are common to all domains: Grid size (km), vertical levels (50,

403 Planetary Boundary Layer $=$ Yonsei, Radiation $=$ Dudhia RRTM, Microphysics $=$ Ferrier,

404 Cumulus physics calls (min.) $=8$, PBL physics calls $=8$.

$405{ }^{1}$ Timestep used at start of a model run before adaptation by the CFL condition.

$406{ }^{2}$ Grid offset from previous domain, units determined by outer domain.

$407{ }^{3}$ No cumulus parameterisation needed at this domain resolution.

$408{ }^{4} \mathrm{~A}$ call time of 0 means at every time-step.

410 From the WMM results we calculate the two-way travel zenith path delays for each day of the 2,3,6,10,14,18,19 December dataset. We also differenced (earlier-later) the pairs of slant wet delay (SWD) fields from the WMM models corresponding to COSMO-SkyMed interferograms

413 and then subtracted the WMM SWD fields from the interferograms. Identical fields would, 414 assuming no other processes introducing signals, result in a perfect compensation for the 415 observed water vapour delay and leave a uniform phase field.

418 MVO operates a network of 14 continuous GPS stations across Montserrat (Fig.2c). The data 419 are telemetered to MVO and processed using GAMIT/GLOBK software (Herring et al, 2010 a, 420 b). At any given interval there is a varying subset of the full GPS satellite constellation visible 421 to each GPS site. The angle of elevation above the horizon of each satellite is variable. A 
422

423

424

425

426

427

428

429

430

431

432

433

434

435

436

437

438

439

threshold elevation angle of $10^{\circ}$ was used to reduce the noise from low-angled paths (Fig.10). The refractive delay of the signal is greater for a satellite-GPS station path with a low elevation angle. An estimate of the Zenith Total Delay (ZTD) (Herring et al., 2010), was made using the GAMIT/GLOBK processing suite incorporate the GPT2 model (Lager et al., 2013), which combines the Global Pressure and Temperature (GPT) and Global Mapping Function (GMF) empirical models, increasing their spatial $\left(5^{\circ}\right.$ vs $20^{\circ}$ grid) and temporal resolutions (annual and semi-annual vs annual variations only), and provides daily a priori values of pressure, temperature, water vapor pressures, and mapping function coefficients with a sampling rate of 30 s corresponding to the GNSS observations sampling rate. To further improve the accuracy of the a priori temperature and pressure values at each GNSS stations, specifically at the time of InSAR image acquisition (5h58 and 17h34 East Caribbean Time), we extract them from the global climatic model NCEP. A comparison of the ZHD values computed using temperatures and pressures from the GPT2 and the NCEF model shows an improvement of up to $\sim 100 \mathrm{~mm}$. The ZWD (in mm of phase delay) equivalence to the water vapour amount (in $\mathrm{mm}$ of precipitable water) is about $7 \mathrm{~mm}$ of phase delay to $1 \mathrm{~mm}$ of water. The values of ZWD are calculated every hour using a piecewise linear function.

The accuracy of the ZWD estimate depends on the location of the satellites. The measurement space for each GPS site is an inverted cone (Fig.10a). The GPS stations are well distributed across the island, with nearest neighbour spacing of $\sim 3 \mathrm{~km}$ (Fig. 2c). Stations on or near the coast will have substantial parts of their measurement space over the sea. Depending on the paths, this could lower the variability of the estimates if the marine troposphere is more uniform than the island troposphere.

The elevation range of the GPS network covers only about half the vertical range of the island's topography (12 to $589 \mathrm{~m}$ a.s.l. compared to 0 to $1083 \mathrm{~m}$ a.s.1.). Steep topography may cause the 
447 line of sight of GPS to become blocked (Fig.10). With increasing elevation of the GPS site, the

448 measured ZWD value will tend to fall. The lapse rate of ZWD is measured by linear regression

449 of the 14 individual station values up to $589 \mathrm{~m}$ a.s.l.. This is justifiable if the water vapour

450 profile is near uniform over this elevation interval, as it is for example up to the LCL in Fig.7.

451 In the following we assume linearity of the lapse rate up to $1083 \mathrm{~m}$ a.s.l. The measured

452 departures from linearity are assumed to be caused by horizontal differences in water vapour

453 delay due to airflow. We wish to capture these lateral variations in ZWD and also vertical

454 modulation of ZWD due to topographic intersection with the water vapour field. A method to

455 achieve this is described in Supplement 1.

456

\section{Surface Topography and Wind}

458

The characteristics of the surface of Montserrat and the COSMO-SkyMed InSAR system

(Table.1) place limitations on the satellite observations of water vapour delay.

\subsection{Viewing Interval and Geometry}

463 The minimum interval between InSAR imaging using the same orbital geometry is about 1246424 days (Pritchard et al., 2018). COSMO SkyMed has a constellation of four satellites and so 465 more frequent revisits were achieved on Montserrat: at intervals of 1- and 4-days. We used 466 seven images (of sufficiently high quality) here, on 2, 3, 6, 10, 14, 18 and 19 December 2014. 467 Two other images were supplied but were too decorrelated to form good quality interferograms.

468 The imaging paths of the COSMO-SkyMed radar are far from vertical and both the resultant 469 slant paths through the troposphere must be simulated in the WMM to give the slant wet delay 470 (SWD). The ascending pass images look at the surface more steeply (26.6 ${ }^{\circ}$ from vertical) than 471 the descending pass images $\left(59.2^{\circ}\right.$ from vertical) (Figs.2c, 11). Thus, the radar paths through 
the ABL are longer for descending passes than for ascending passes. This would have no effect

473 if the 3D water vapour fields were identical at the times of the two images forming the

474 interferogram. But generally, temporally separated water vapour fields do vary spatially (e.g.

475 Minder et al. 2013), so that we would expect the longer paths of the descending pass

476 interferograms to create more spatial variance in the resulting delay fields. The mountain axis

477 of Montserrat is oriented about $350^{\circ}$, roughly perpendicular to the usual easterly trade wind

478 direction. This is also perpendicular to the azimuth of the radar look direction in the ascending

479 pass but about $20^{\circ}$ off the perpendicular for the descending pass (Fig.2c). Water vapour-derived

480 variability should increase in descending pass interferograms as the radar path becomes more

481 oblique to the mountain axis of the island and a longer path over the land surface with its high

482 variability of water vapour. So, from both these geometrical effects we would expect the

483 descending pass interferograms to show a greater amplitude of phase variance than for the 484 ascending pass ones, other factors being equal.

485

W

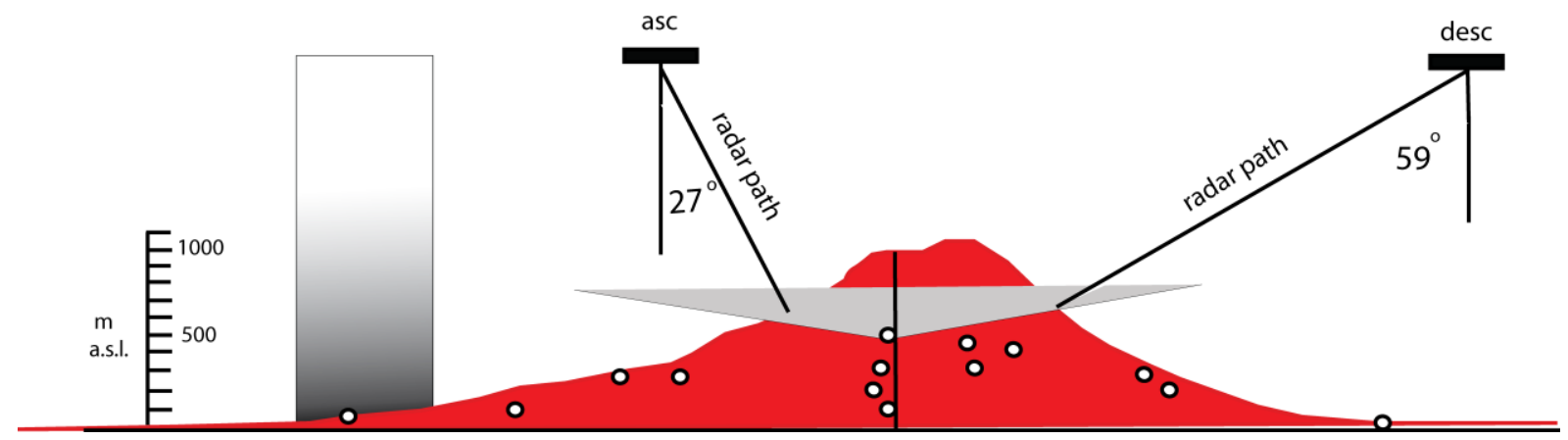

Fig.10 True scale cross section (W-E) through Montserrat at SHV (the location shown in Fig.2c). The ascending (27 degrees from vertical) and descending (59 degrees from vertical) radar slant paths are shown schematically.

On the western side of the section is a gradational column schematically intersected by the surface of the SHV volcano. This is shown to emphasize the nature of the problem if the water vapour field is simply layered and the 

$x, y$-plane). Note that there are no receivers above $\sim 600 \mathrm{~m}$ a.s.l.. The grey triangle represents the apex of the

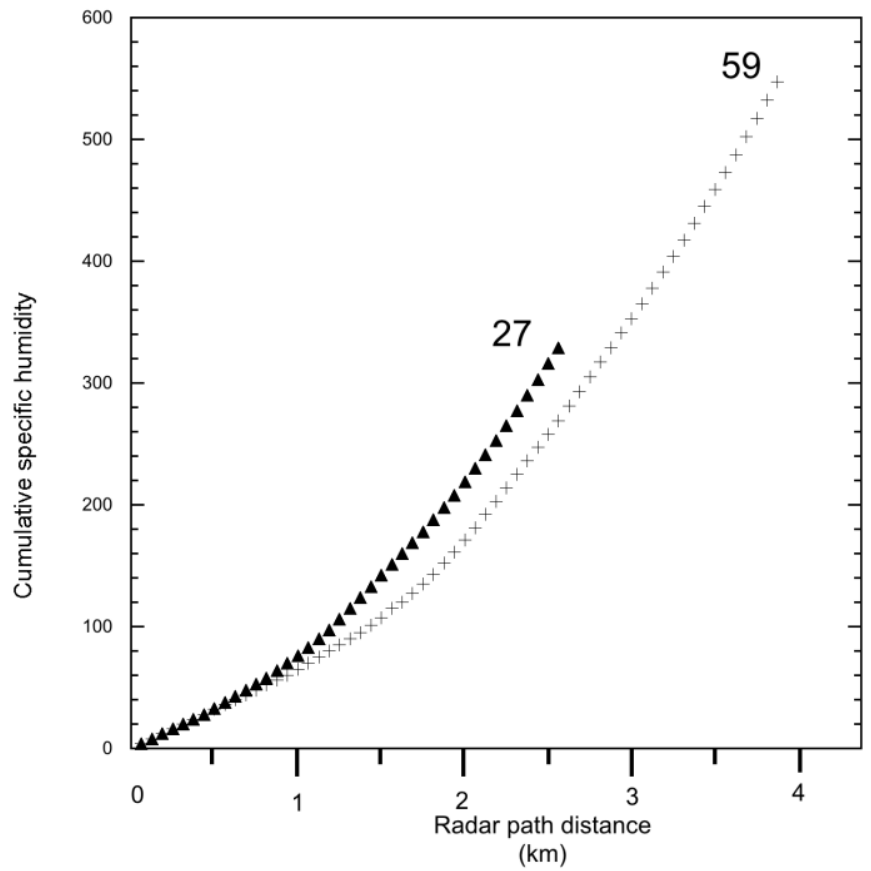

Fig.11 Plot of the cumulative amount of specific humidity water vapour against radar path distance. The origin of the plot lies at a location about $3.5 \mathrm{~km}$ above the ground surface. The two curves (labelled 27 and 59) correspond to ascending and descending path satellites respectively, as shown in Fig.10. The two curves are similar until

503 about $800 \mathrm{~m}$ when they start to diverge, the ascending path radar encountering water vapour faster until about

$5042.5 \mathrm{~km}$ when it reflects from the ground surface. The descending path radar continues for just over another 505 kilometre until it too hits the surface. The "59" radar records about 1.66 more water vapour than the "27" radar.

\subsection{Wind Speed}

508 The speed of the wind has been shown to affect the dynamics of orographic convection in 509 several studies of the atmosphere around the mountains of the Lesser Antilles (Smith et al. 2012; Minder et al., 2013; Cécé et al., 2014). The orientation of convection is highly 
511 asymmetric (Nugent et al., 2014). At low wind speeds $(<5 \mathrm{~m} / \mathrm{s})$ solar surface heating drives convection with surface convergence forming clouds that are slowly moved downstream by the mean wind (Fig.8a). At high wind speeds ( $>7 \mathrm{~m} / \mathrm{s}$ ) air is forced upward on the windward side

514 forming clouds and high humidity there, whilst to leeward there is plunging flow, reduced cloud 515 formation due to evaporation and reduced water vapour (Fig.8b). We measured the wind 516 velocities during the satellite overpasses (Table 2) from the ground surface near sea level, from 517 an airport anemometer close to the ground surface at about $160 \mathrm{~m}$ a.s.l. and from radiosonde 518 observations above Guadeloupe, about $100 \mathrm{~km}$ SSE of Montserrat. Following Nugent et al. 519 (2014) we use the average wind in the lower ABL (<600 m a.s.l.) to determine the tripartite 520 classification of low, medium and high wind speeds. Wind speeds were "low" on 3 and 18 521 December, "high" on 14 and 19 December and "medium" for the other three days (Table 5) . 522 The wind direction was from east to west for six of the observation days, but with considerable 523 scatter. The wind direction changed from west to east on 6 December during the passage of a 524 low-pressure system to the southeast of Montserrat.

525 Wadge et al., (2006) collected wind speeds and strength at the time of acquisition of ERS C526 band radar images during 1998 - 2000 (Table 4). These show that the eastern quadrant 527 dominated the wind directions and strengths on Montserrat.

Table 4. Wind speed by quadrant at the time of acquisition of ERS C-band images (between March 1998 -

November 2000) over the SHV on Montserrat (data from Wadge et al., 2006).

\begin{tabular}{|l|l|l|l|l|}
\hline Wind speed (m/s) & North & East & South & West \\
\hline Low $(<5)$ & 3 & 1 & 1 & 1 \\
\hline Medium (5-7) & 1 & 6 & 0 & 0 \\
\hline High $(>7)$ & 2 & 13 & 2 & 0 \\
\hline
\end{tabular}


534 Table 5. Wind observations at the times of imaging in Dec. 2014.

\begin{tabular}{|l|l|l|l|}
\hline Date & $\begin{array}{l}\text { Wind } \\
\text { strength }\end{array}$ & $\begin{array}{l}\text { Wind } \\
\text { Direction }\end{array}$ & View/Time $^{2}$ \\
\hline $02 /$ Dec/2014 & M & East & A \\
\hline $03 /$ Dec/2014 & L & East & A \\
\hline $06 /$ Dec/2014 & M & West & D \\
\hline 10/Dec/2014 & M & Southeast & D \\
\hline 14/Dec/2014 & H & Southeast & D \\
\hline 18/Dec/2014 & L & East & A \\
\hline 19/Dec/2014 & H & East & A \\
\hline
\end{tabular}

1. $\mathrm{H}=$ high $\left(>7 \mathrm{~ms}^{-1}\right), \mathrm{M}=$ moderate $\left(7-5 \mathrm{~ms}^{-1}\right), \mathrm{L}=\operatorname{low}\left(<5 \mathrm{~ms}^{-1}\right)$

536 2. $\mathrm{A}=$ ascending pass/sunrise, $\mathrm{D}=$ descending pass/sunset

The above evidence shows that strong, easterly winds are most likely to develop strongly asymmetrical convection patterns. We use data from the example of a strong, easterly wind on Dominica modelled by WRF (Minder et al., 2013) shown in Fig.8 which we take to be

541 representative of behaviour at Montserrat. Using the geometry of the east-looking $\left(23^{\circ}\right)$ 542 ascending radar data and the west-looking $\left(59^{\circ}\right)$ descending pass data we find that the water 543 vapour fields detected by the descending pass radar are 1.66 greater than the ascending pass

544 case (Fig.11). It may be possible to extract some simplified states from this asymmetrical 545 behaviour that can be quickly used to predict a 3D water vapour field using ICTZ, trade wind 546 and precipitation, without using a full numerical weather prediction approach.

\subsection{Diurnal Cycle}

549 The potential effect of the diurnal cycle on radar refractivity is two-fold. Firstly, the state of the 550 ABL over the island encountered by the radar will depend on the timing of the satellite overpass 
relative to the cycle (Table 1). In the case of the COSMO-SkyMed data we use, the ascending overpasses of the satellite were at 05:58 local time, just before sunrise at 06:20, at what should

553 be a time of low refractivity noise (Wadge et al., 2016). The descending overpasses were at 554 about 17:34 local time, close to sunset at 17:35, again a time of expected low refractivity noise. 555 On the other hand WRF simulations of sunrise temperatures (e.g. Gonzalez et al., 2013) can 556 show abrupt inflections and noisier behaviour. Secondly, a satellite with an overpass later in 557 the morning, say, could be sampling a much more turbulent ABL than earlier in the cycle after 558 thermal convection had developed. However, if the trade wind speed was high, orographically559 forced convection may occur whatever the time of the cycle. The studies of katabatic flow at 560 Guadeloupe (Basse Terre) show that the period from December to March is the most prone to 561 such flows (d'Alexis et al., 2011).

\section{Results}

$564 \quad 5.1 \quad$ Water vapour fields on individual days

565 Fig.12 shows radiosonde-derived humidity mixing ratio profiles over land (Guadeloupe) 566 measured at 08:00 local time on the days of radar imaging (within two hours of the ascending 567 pass images on 2, 3, 18 and 19 December and within about nine hours of the descending pass 568 images of $6,10,14$ December). Overall the humidity mixing ratio profiles have mean values in 569 the range $15-16 \mathrm{~g} / \mathrm{kg}$ between 0 and $0.6 \mathrm{~km}$ altitude. The humidity decreases rapidly and 570 smoothly up to altitudes of about $2 \mathrm{~km}$, above which it falls more slowly up to altitudes of 4-9 $571 \mathrm{~km}$ before dropping to values of $<1 \mathrm{~g} / \mathrm{kg}$. The individual humidity profiles tend to have 572 characteristics that match the prevailing wind speed. The profiles of 6 and 10 December are 573 very similar with notably more humidity at higher altitudes $(4-9 \mathrm{~km})$ than on the other days.

574 Both days have a moderate-wind range. The two low-wind days (3 and 18 December) show 575 very similar profiles with high amplitude inversion structures between 2 and $5.5 \mathrm{~km}$. The two 
576 high-wind days (14 and 19 December) also have very similar profiles, falling to very low

577 humidity values above $4 \mathrm{~km}$. In figure 13 we compare the WMM ZWD fields with the 578 equivalent ZWD fields derived from GPS at the times of the seven satellite overpasses (Table

579 1). We can see that the effect of topography in both sets of data is to reduce ZWD value with 580 elevation at both SHV and Centre Hills (Fig.2c), as we expect. The ranges of ZWD values, due 581 to topography, calculated by both methods for the seven days give similar average values: $83 \pm$ $5827 \mathrm{~mm}$ for GPS and $79 \pm 14 \mathrm{~mm}$ for WMM. This suggests that both techniques record similar 583 gradients of water vapour content.

584
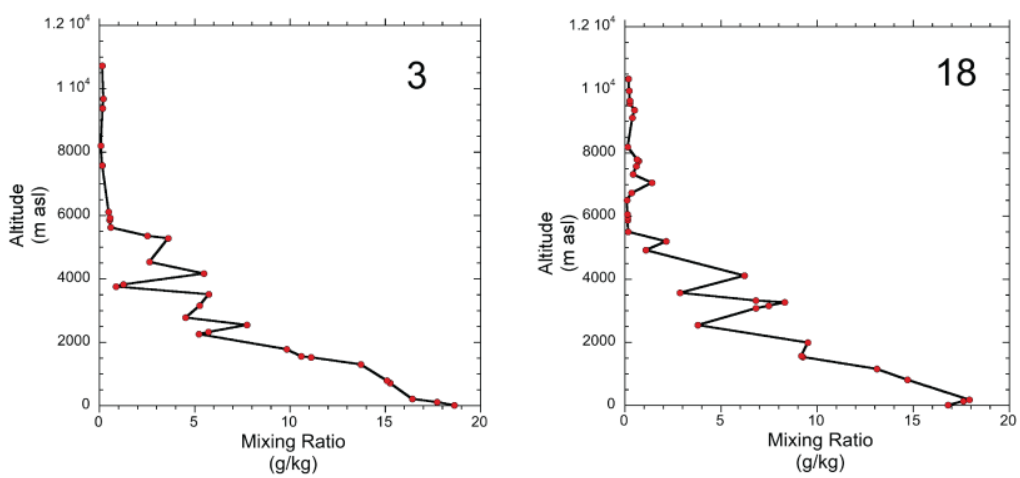

Low
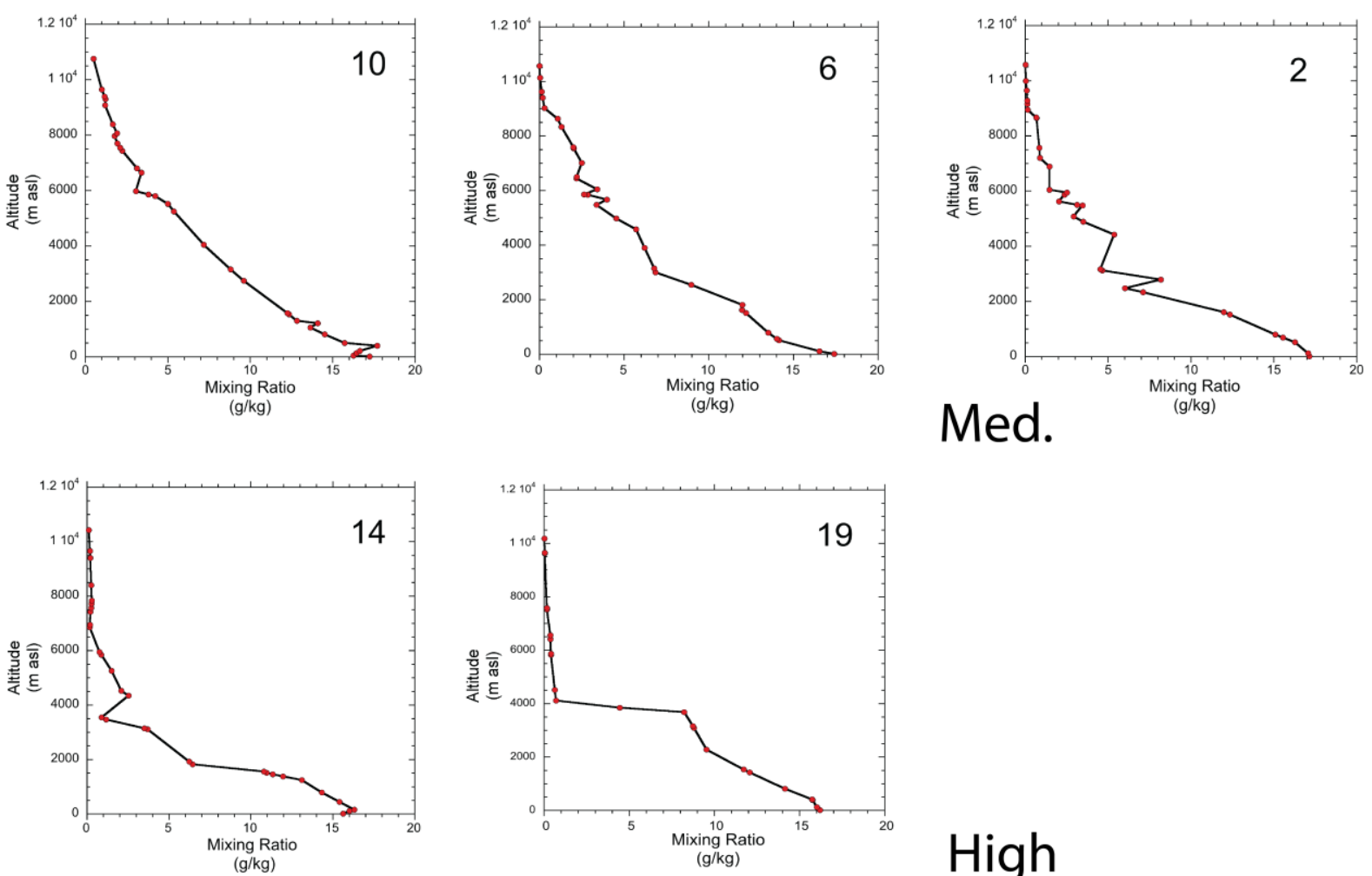

High 
Fig.12 Humidity mixing ratio profiles from radiosondes launched at Le Raiset, Guadeloupe at 08:00

local time on the days of the radar imaging in December labelled in the upper right corner of each panel. Profiles are arranged in high-, medium- and low-wind speed rows.

The absolute values of ZWD from the WMM simulations are generally higher than those from

591 the GPS method: the difference is least on 18 December (15 mm) and most on 14 December

592 (84 mm). When these differences for each of the seven days are plotted against wind speed

593 (Fig. 13 lower left graph), the difference in ZWD values are shown to diverge with increasing

594 wind speed at a rate of about $11 \mathrm{~mm} / \mathrm{m} / \mathrm{s}$. This bias associated with wind speed is unexpected.

595 The WMM may be lifting too much water vapour from lower levels during high winds.

596 Alternatively, the bias could represent a faulty assumption of the linearity of the water vapour

597 lapse rate in the GPS-based method, for example, in the un-sampled elevation range between 598 about 600 and $1100 \mathrm{~m}$ a.s.l. there is a much higher water vapour content at times of high wind 599 speed than expected from a linear extrapolation from lower elevations.

600 The wind on 6 December was from the west (Table 5), as opposed to the usual easterly trade 601 wind direction. In the WMM simulation (Fig. 13) the low levels of ZWD associated with the 602 SHV topography are displaced to the southeastern corner of the island compared to days when 603 the wind was easterly, for example, on 10 December. This is particularly so for the 19 December 604 case, which had high speed, easterly winds and high ZWD values on the southeast, windward 605 coast, equivalent to the high wind-speed case from Dominica illustrated in Fig.8b. Thus, out of 606 the seven cases, the one with clear evidence of reversed trade wind flow (6 December) generates 607 the expected reversal of ZWD asymmetry in the WMM model. 


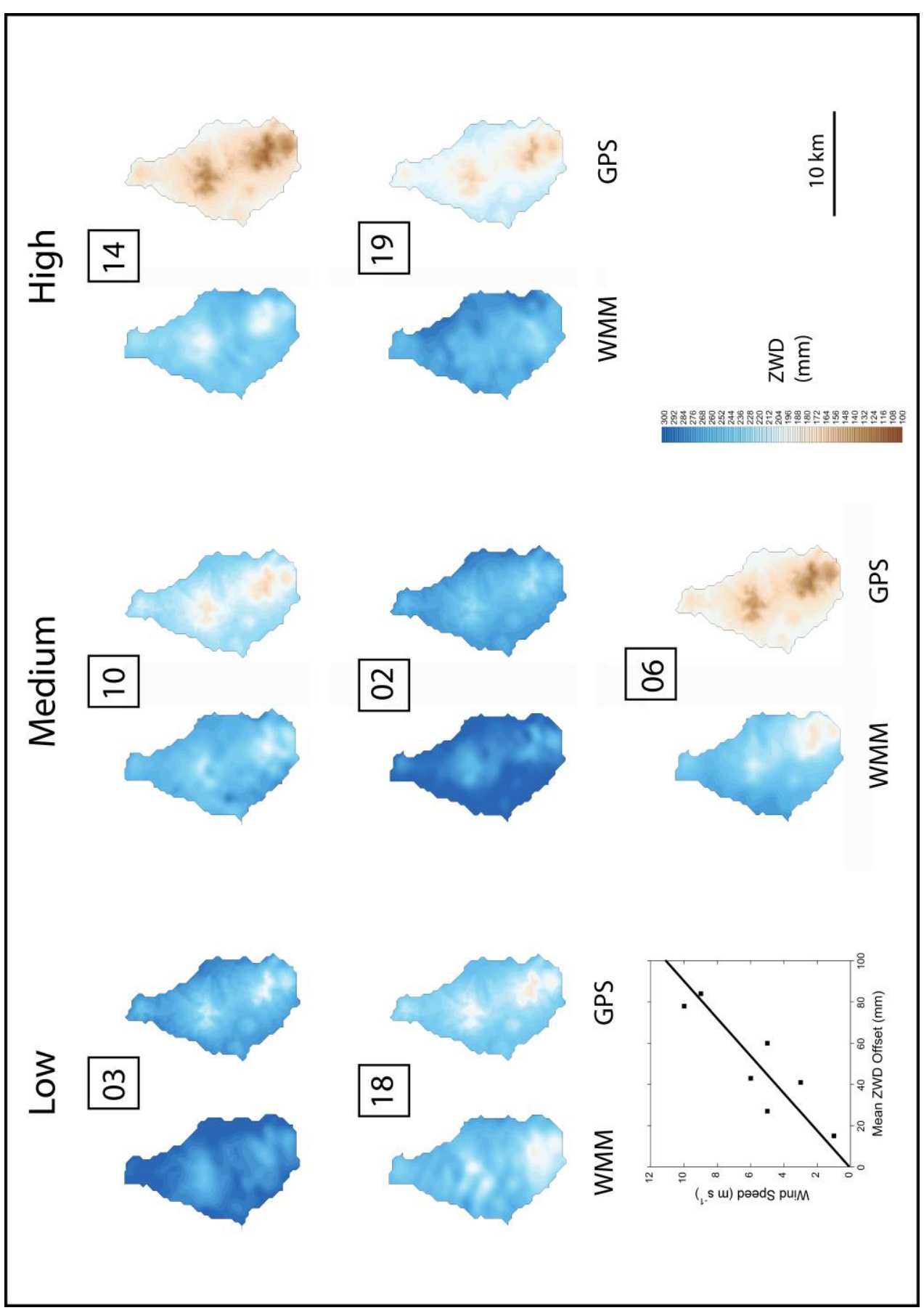

615 Fig. 13 Pairs of maps of ZWD over Montserrat during December 2014. The date is given by the number

616 between each pair. The left image of each pair is the WMM simulation and the right image is from the

617 GPS method, as described in the text. The pairs are arranged in three columns according to the "low,

618 medium and high" wind speeds on those days (Table 5). The ZWD data are plotted to a horizontal 619 posting of $300 \mathrm{~m}$, the finest model resolution of the WMM. The colour scale of ZWD values shown on 
the bottom row is common to both sets. The graph at the bottom left is of ABL wind speed versus the mean offsets in ZWD values between the two methods for the seven days.

5.2 WMM differential water vapour fields at zenith

624 The radar image pairs: 2-3, 6-10, 10-14, 18-19 December were chosen for interferogram creation. The WMM-derived maps of ZWD differences (earlier - later) correspond to the four intervals (Fig. 14). Firstly, we compare these ZWD differences with those between the integrated humidity mixing ratios determined by radiosonde profiles between 0 and $2 \mathrm{~km}$ a.s.l.

628 (Fig. 12), taken to be representative of the humidity in the ABL. These differential values are: $62902-03=+1.4,06-10=-3.5,10-14=+5.4$ and $18-19=0.0 \mathrm{~g} / \mathrm{kg}$. The positively-valued pairs 630 (02-03 and 10-14) show similarly valued ZWD (Fig.14) whilst the negatively-valued pair (06631 10) corresponds to mainly negative ZWD values and the $18-19$ pair is dominated by negative 632 ZWD values unlike the radiosonde pair $(0 \mathrm{~g} / \mathrm{kg})$. Secondly, we assess the spatial patterns of 633 Fig.14. The 2-3 field is of low amplitude with negative values in the east and positive values in 634 the west. A similar pattern is seen in the 6-10 field, except for much larger negative values on 635 the southeast coast. This is the same WMM-derived feature discussed above and as seen in 636 Fig.13 which is probably the result of westerly winds on 6 December and easterly winds on 10 637 December, shifting the low ZWD values above the volcano from the east on the 6 December to 638 the west on the 10 December. The 10-14 field is largely positive, with much more humid values 639 on 10 December. In contrast, the 18-19 field is dominantly negative with generally more humid 640 values on the $19^{\text {th }}$ relative to the $18^{\text {th }}$. Both the $10-14$ and the $18-19$ difference fields have most 641 of their variability at the $1 \mathrm{~km}$ scale rather than the island-scale patterns of 2-3 and 6-10, perhaps 642 due to model convection noise driven by high wind speed on 14 and 19 September. 

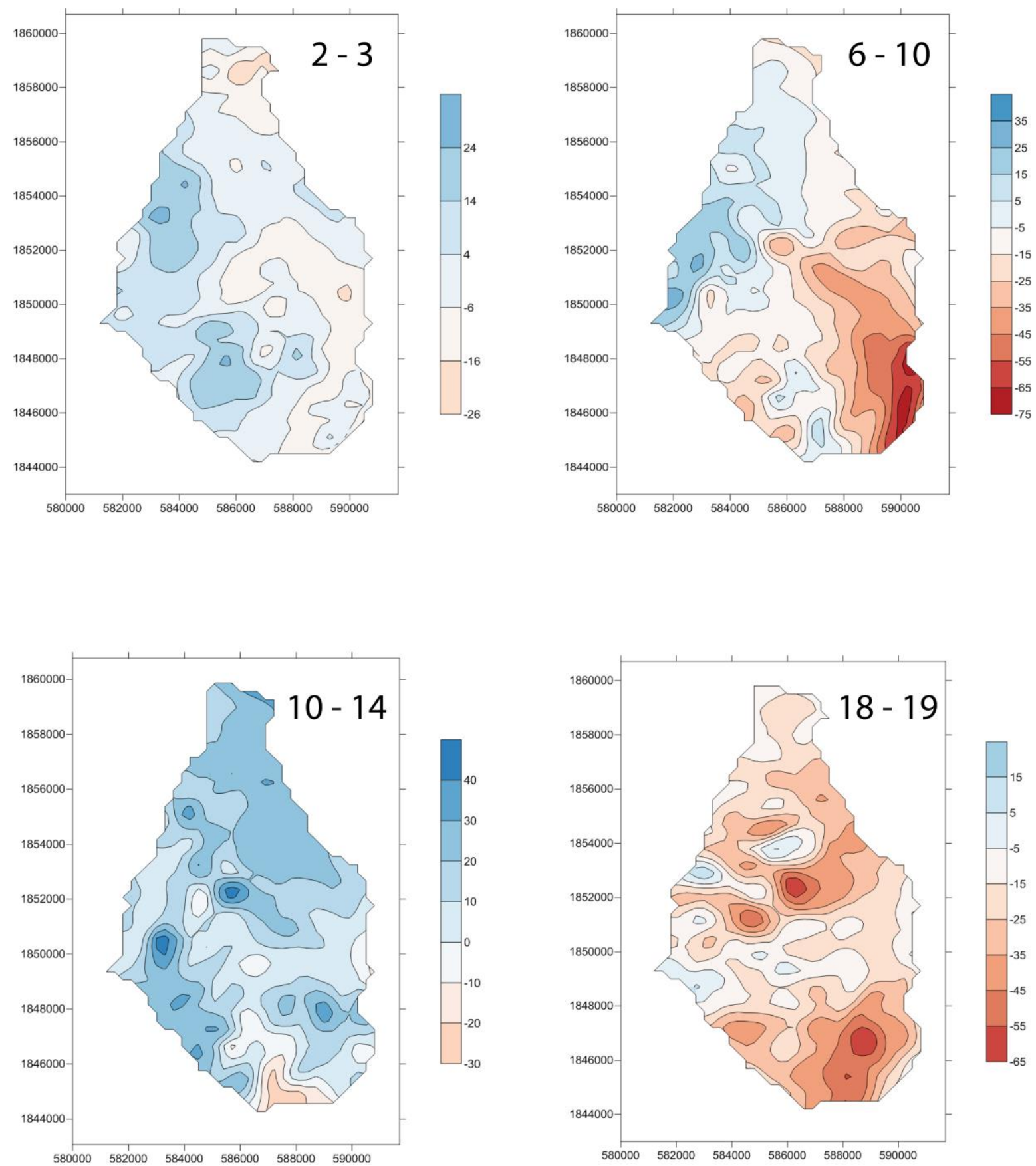

644

645 Fig. 14 WMM-derived ZWD difference fields for four pairs of dates corresponding to the

646 interferograms. Differences in mm (earlier-later). Time intervals in December (days) are given in the top right of each panel. Local grid values in kilometres. Values in lower corner boxes are the rms delay values also shown in Table 6. 

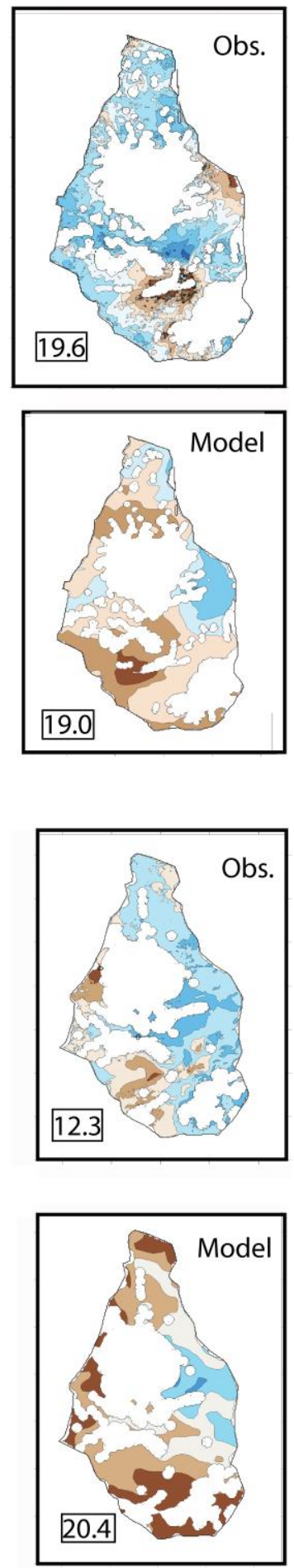
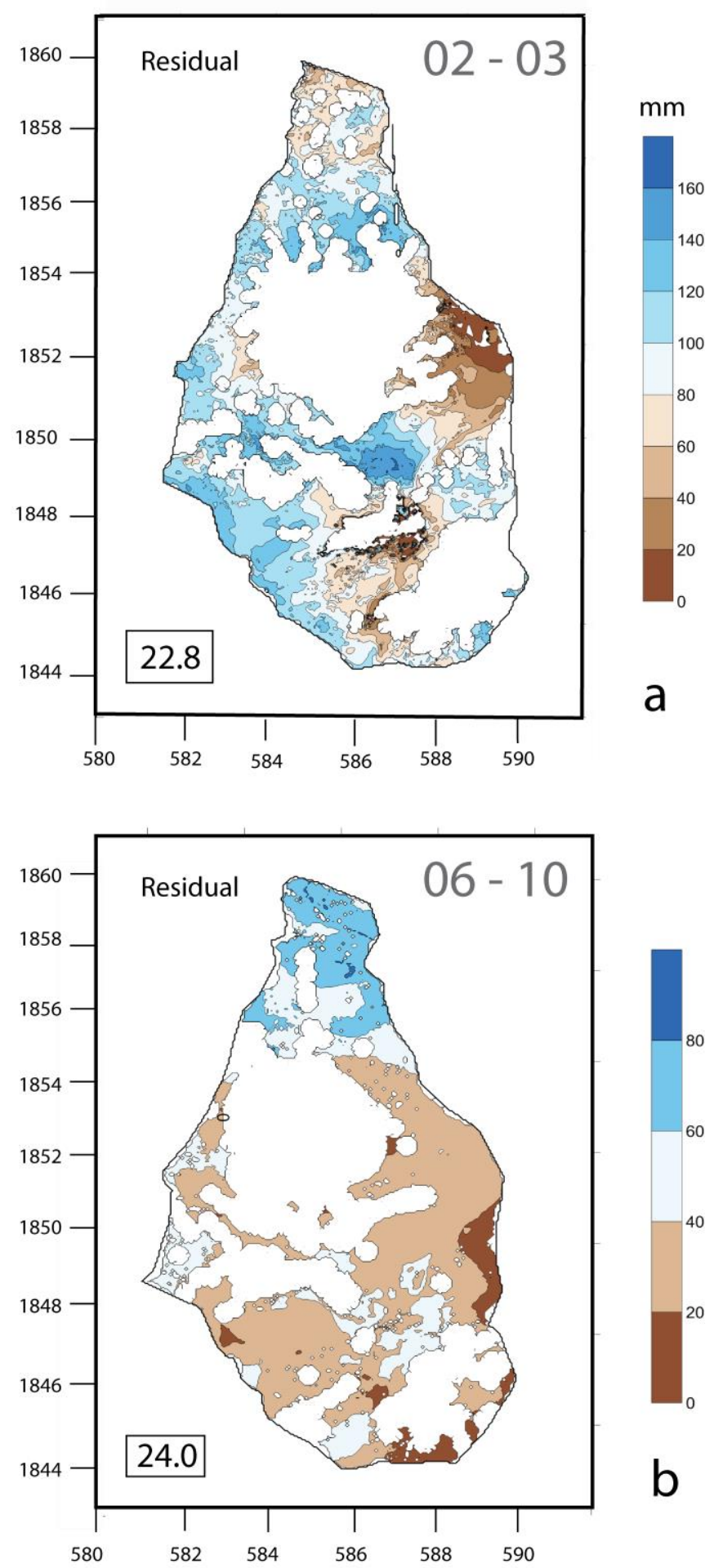

652 Fig.15 Slant wet delay fields for observed (Obs.) interferogram data, modelled (Model) WMM data

653 and the Residual (Observed - Modelled) fields for (a) the 2-3 December and (b) the 6-10 December

654 intervals. Differences in mm (earlier-later). Local grid values in metres. Values in lower corner boxes 655 are the rms delay values also shown in Table 6. 

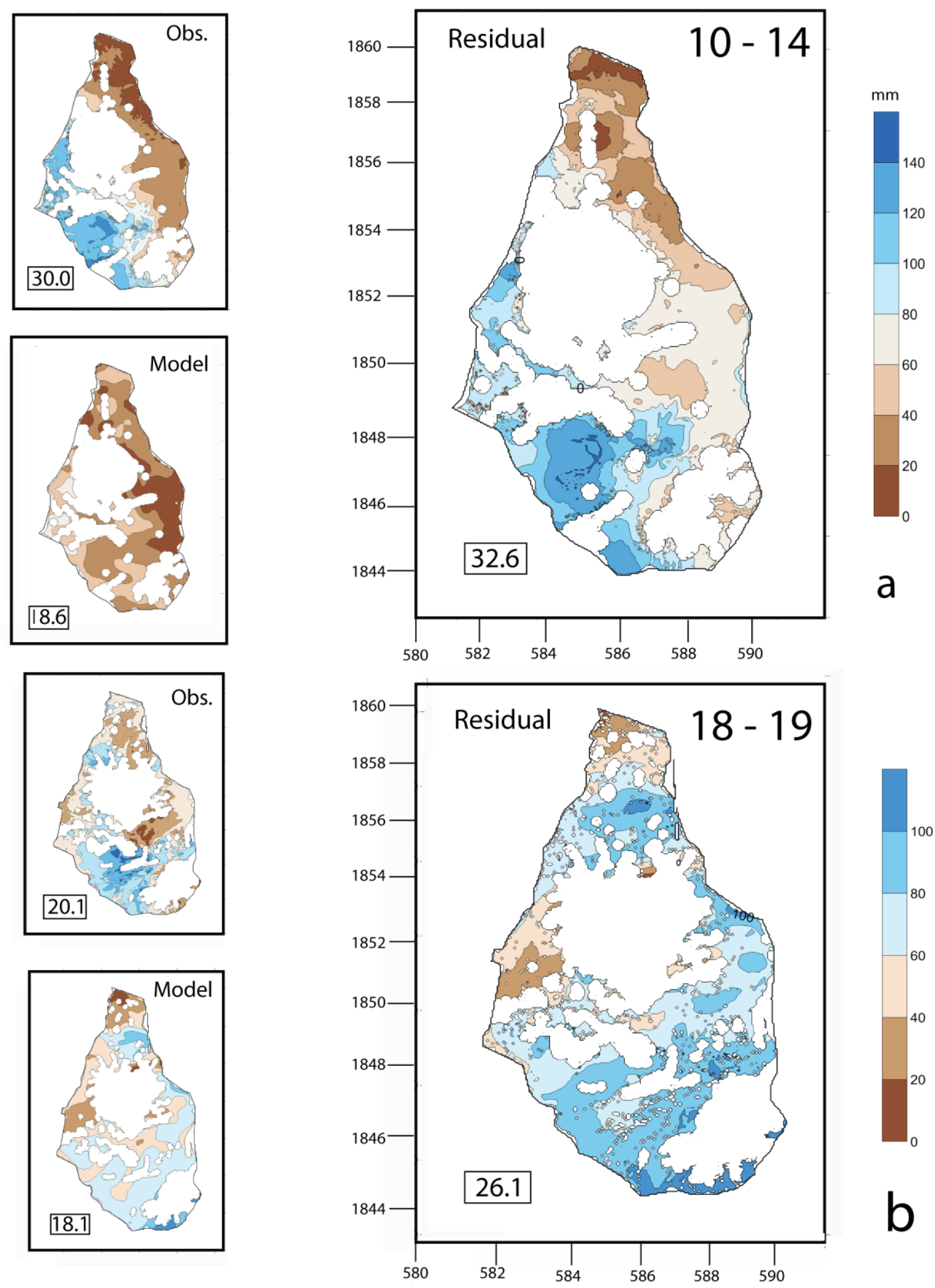

658 Fig.16 Slant wet delay fields for observed (Obs.) interferogram data, modelled (Model) WMM data and the Residual (Observed-Modelled) fields for (a) the 10-14 December and (b) the 18-19 December 
intervals. Differences in mm (earlier-later). Local grid values in kilometres. Values in lower corner

665 We now consider the observed delay fields of the COSMO-SkyMed pairs. Specifically, along 666 the slant of the radar paths, $26.6^{\circ}$ and $59.2^{\circ}$ from zenith. The residual fields created by 667 subtracting the WMM - SWD field from the equivalent field observed by COSMO-SkyMed, 668 including the incoherence masks, are shown in Fig.s 15, 16. The observed and modelled fields 669 are quite similar for 06-10, 10-14 and 18-19 periods, but not for 02-03.

670

$2-3$ December

672 The only obvious feature in common between the observed and modelled delay fields is that

673 the lowest differences are seen around the upper slopes of the volcano. Generally, elsewhere 674 the modelled differences are smaller than the observed differences. The overall range of 675 differences is greatest in this pair of dates.

676

6 - 10 December

678 The observed and modelled SWD fields show similar patterns. In the observed field there is a 679 strong gradient across the island with the eastern side of the island having the greatest 680 differences and the south-western side the least change across the two dates. This is also seen 681 in the model results but for a more restricted area on the middle, leeward slopes. The 682 northernmost part of the island shows a contrasting pattern with the highest residuals. 683 $10-14$ December 
685 The observed SWD field shows a strong gradient of water vapour, high in the southwest, low

686 in the northeast. The modelled version is similar but of a smaller magnitude. The pattern of 687 differences for these 5 days is a reversal of that shown by the 6-10 December interferogram, 688 with a lowest difference on the eastern slopes. This suggests a source that is the common date 689 (10 December) shared by the two intervals. The model field has the smallest range. The 690 humidity mixing ratio is considerably greater on 10 December that on 6 or 14 December 691 (Fig.12), with an inversion horizon $2 \mathrm{~km}$ higher than that of 14 December (4 km).

\section{$69318-19$ December}

694 On these two days the phase differences were similar in both observed (InSAR) and model, 695 high in the south of the island and low in the north, though the WMM range is generally lower 696 than the InSAR result.

The range of values in the observed and modelled delay fields is similar, approximately 80-120 mm. The two descending pass interferograms (06-10 and 10-14) show strong ENE-WSW gradients across the island (Figs.15, 16) with opposite polarities. The two pairs share the same 10 December image, which is the most likely explanation for this pattern. The two ascending pass delay fields (02-03 and 18-19) have shorter intervals (1-day) but less distinct gradients matching the trade wind orientation.

The WMM model delay fields show some structural similarities to those observed by radar. For 706 example, the $06-10$ WMM field shows higher delay values (more water vapour) in the central windward side of the island, as does the observed field. The WMM field for 18-19 December shows a lower delay value (less water vapour) in the northern half of the island compared to the radar-derived field. The radar fields across the highest parts of SHV tend to show the 
710 strongest gradients, suggestive of the abrupt change in flow regime across the island's

711 topographic divide as shown in Fig.9 b. This is also seen in some of the WMM fields as in 02-

71203 and 06-10, but the gradient is less steep.

714 The effectiveness of reducing the atmospheric component of phase delay in the interferograms

715 is assessed by calculating the root mean squared (RMS) error and the percentage of pixel delay

716 (PPD) between the interferograms and the WRF simulations across the island (Table 6). PPD

717 is defined here as the pixel-wise offset in the difference field from zero expressed as a

718 percentage, where $100 \%$ would mean a difference field at zero (perfect match) and $0 \%$ would

719 mean all pixels in the difference image would exceed the maximum bounds of the residual

720 image. We expect a small delay RMS and a high PPD if WRF performs well. The RMS of the

721 radar interferograms has a mean value of $20.5 \mathrm{~mm}$, less than that of the residual, $26.4 \mathrm{~mm}$ Using

722 the PPD metric the 06-10 value has the most accurate residual of $80.95 \%$, values for 6-10, 10 -

72314 and $18-19$ intervals of $80.9 \%, 65.42 \%$ and $76.82 \%$ respectively.

Table 6. RMS delay differences for image interferograms with ambient wind speed.

\begin{tabular}{|c|c|c|c|c|c|c|}
\hline $\begin{array}{l}\text { Dates for each } \\
\text { pair }\end{array}$ & $\begin{array}{l}\text { COSMO- } \\
\text { SkyMed } \\
(\mathrm{mm})\end{array}$ & $\begin{array}{l}\text { WMM } \\
(\mathrm{mm})\end{array}$ & $\begin{array}{l}\text { Residual } \\
(\mathrm{mm})\end{array}$ & $\begin{array}{l}\text { PPD \% } \\
(\mathrm{mm})\end{array}$ & $\begin{array}{l}\text { Average daily } \\
\text { wind speed } \\
\text { difference }(\mathrm{m} / \mathrm{s})\end{array}$ & Wind comments \\
\hline $2-3 / \mathrm{Dec} / 2014$ & 19.58 & 19.01 & 22.78 & 64.51 & 4.8 & More E-W flow than S-N \\
\hline 6-10/Dec /2014 & 12.29 & 20.41 & 24.03 & 80.95 & 9.5 & $\begin{array}{l}\text { Strong E-W flow, little S-N } \\
\text { flow }\end{array}$ \\
\hline 10/14/Dec//204 & 30.05 & 18.64 & 32.61 & 65.42 & 6.7 & Strong S-N flow \\
\hline 18/19/Dec/2014 & 20.14 & 18.10 & 26.06 & 76.82 & 2.7 & Similar S-N flow to E-W \\
\hline
\end{tabular}

727 Table 7 shows the relative proportions of slant wet delay (SWD), liquid wet delay (LWD) and

728 hydrostatic delay (HSD) calculated from the WMM difference fields corresponding to the dates 
of the four interferograms. LWD is calculated using the delay coefficient for cumulus cloud

730 from Hanssen, (2001), that is the most appropriate (0.7). As expected, SWD is about an order

731 of magnitude larger than LWD and HSD values. December is just

Table 7. Percentage differences of total delay within the WMM apportioned to

Slant Wet Delay (SWD), Liquid Water Delay (LWD) and Hydrostatic Delay (HSD).

\begin{tabular}{|l|l|l|l|}
\hline Dates & SWD \% & LWD \% & HSD \% \\
\hline $2-3 /$ Dec/2014 & 81.9 & 11.3 & 6.8 \\
\hline $6-10 /$ Dec/2014 & 86.5 & 9.5 & 4.0 \\
\hline $10-14 /$ Dec/2014 & 88.0 & 7.1 & 4.9 \\
\hline $18-19 /$ Dec/2014 & 84.7 & 9.8 & 5.4 \\
\hline
\end{tabular}

735

after the end of the wet season in Montserrat (Fig.4). Images of precipitation from the TRMM

satellite show that the only regional rainfall over the period occurred on 6 December during the passage of a mesoscale feature that skirted Montserrat to the south and also produced westerly winds. The proportion of LWD (11 - $7 \%$ ), generally derived from the WMM, is not negligible.

\section{Discussion}

744 6.1 Understand where and when tropical water vapour originates.

745 The tropics contain the highest levels of atmospheric water vapour as it evaporates above warm ocean. Our test case SHV volcano, Montserrat lies in the western tropical Atlantic and is subject to the migration of the ITCZ, northwards during the wet season and southwards in the dry season. The main effect of the ITCZ is to cycle rainfall and precipitable water vapour, in the case of Montserrat causing rainfall rates of about $1 \mathrm{~mm} /$ day in the dry season to about $5 \mathrm{~mm} /$ day in the wet season. Because of its differential nature, InSAR will tend to give the largest 
atmospheric signals, with one image from the peak and one from the trough of the ITCZ cycle (e.g. Fig.3). A detailed study of the same effect from Fogo volcano in the eastern tropical Atlantic (Heleno et al., 2010) indicates about 50-30 mm of phase change could be possible at Montserrat, similar to the findings of Wadge et al. (2006). Also the tropical seas of southeast Asia contain a large number of volcanoes, many on islands, that are affected by the ITCZ. The periodicity and amplitude of the ITCZ humidity signal (Martinez et al., 2019; Pausata and Camargo, 2019) are well characterized and hence provide a way to estimate the local scale of water vapour forcing as it affects InSAR on volcanoes.

\subsection{Measure and simulate water vapour over a small mountainous tropical volcano}

There is no easy way to separate the phase delay differences of the two images contributing to the interferogram once its components are combined. Typical ranges of water vapour content variation across Montserrat are about $100 \mathrm{~mm}$. The humidity mixing ratios increase from $\sim 5-$ $1 \mathrm{~g} / \mathrm{kg}$ at the top of the ABL ( 2 - $4 \mathrm{~km}$ altitude) to about $18 \mathrm{~g} / \mathrm{kg}$ at sea level. (Fig.12)

766 In our experiment we used X-band radar in both ascending and descending paths. The ascending 767 path of the satellites follow an azimuth of $349^{\circ}$ at an angle of about $27^{\circ}$ to the zenith and the 768 descending path an azimuth of $011^{\circ}$ and an angle of about $59^{\circ}$ to the zenith. As a result, the 769 length of the descending path through the troposphere is about 1.7 greater than that experienced by the ascending path. The water vapour encountered should be equivalent to this ratio if the

771 path has equivalent specific humidity. The horizontal orientation of the mountain chain forming 772 Montserrat is about $350^{\circ}$, roughly parallel to the ascending radar path, whilst the descending 773 radar path, is oriented about $20^{\circ}$ anticlockwise to the topographic axis. The WMM has 5 nested 774 levels, the first $0.3 \mathrm{~km}$ grid being the one that just covers Montserrat. Whilst this $300 \mathrm{~m}$ scale 775 is adequate for many applications, it is of less value at representing convection simulating 
clouds, such as the growth of clouds above a heated ground surface (Kirshbaum and Smith, 2009).

6.3 Show how model and observational variations of humid flow depend on the scale and setting of this flow.

781 The direction and speed of the winds, the orientation of the topography, and the diurnal cycle of water vapour are major factors in controlling humid flow. Trade winds blowing from the east dominate in Montserrat. These winds tend to produce asymmetrical humidity fields, with higher values over the windward (eastern) slopes and lower values on the leeward (west) side, particularly when the wind speed is high $(>7 \mathrm{~m} / \mathrm{s})$. Lee waves tend to form on the leeward side with cloud enhancement and precipitation. At lower wind speeds diurnal solar heating tends to form above hot land surfaces with long trails of clouds converging downwind about $30-40 \%$ of the time (Kirshbaum and Fairman, (2015). Out of the 7 days of radar measurements, one (6 December) experienced wind from the west (due to a regional system to the southeast). This had a clear impact on the humidity field, creating low specific humidity over the south-eastern

791 flank of the island (Figs. 13,14). The asymmetry of the humidity field during normal trade wind days produces specific humidity values that are greater on the windward relative to the leeward side.

Accurate WMM slant delay fields should be identical to those of the contemporaneous interferograms. However, they differ quite significantly as seen in Figs. 15, 16 and Table 6. The standard deviations of the residual images are marginally greater than those of the WMM and InSAR images (Table 6). Spatial offsets of only a few hundred metres in these models are sufficient to generate large local gradients in the humidity fields, e.g. Fig. 16. This misfit has been observed in other interferogram-based studies (e.g. Bekaert et al., 2015). It was thought that the relatively high resolution of the WMM would help mitigate this. But perhaps the 300 
$801 \mathrm{~m}$ horizontal resolution of the model was still too coarse to capture the flow modifying terrain sufficiently well. The lack of detail in the WMM (300 m resolution) is an explanation of why

803 the range of model specific humidity values tend to be less than the InSAR measurements $(\sim 2 \mathrm{~m}$

804 resolution). In order to capture finer details in the dynamic water vapour profile, alternative 805 approaches, or a hybrid of them, may be adopted such as the use of large-eddy simulation 806 (Kirshbaum and Smith, 2009), statistical models or empirical image processing techniques 807 although these techniques present their own problems.

808

809

\section{Conclusion}

Unknown amounts of water vapour in the troposphere introduces error in the measurement of geodetic signals, particularly at volcanic islands such as Montserrat. Using InSAR (and GNSS) measurements and WRF modelling, at the time of the overpasses of radar-bearing satellites, we examined the temporal and spatial factors leading to the variability of water vapour. The

816 dominant process that controls the annual water cycle at Montserrat is the ITCZ. This brings an irregular annual dynamic behaviour of water vapour, rainfall and winds. Low values of water vapour occur during the boreal winter and spring and high values in the boreal summer and autumn. The range of specific humidity measured globally by the ITCZ is about $6 \mathrm{~g} / \mathrm{kg}$, consistent with that measured locally at Montserrat (and Fogo). Improved knowledge of the

821 ITCZ's climatology and local behaviour would help to forecast water vapour error budgets.

822 Another important factor after water vapour distribution is the trade winds. In the vicinity of 823 the eastern Caribbean the trade winds blow from the east northeast. This is often modified as 824 the ITCZ passes the equator with east southeast flow at higher speeds in summer. Occasionally, 825 the flow is markedly changed or entirely reversed by regional features. This occurred during 
one day of our experiment (6 December) in which the island-wide wind pattern was reversed.

827 It produced a weak westerly flow and concentration of water vapour in the west, the opposite 828 of the "normal" trade wind pattern.

829 Most days the rising sun coincides with strong surface heating and the ensuing development of 830 both maritime and terrestrial-generated convection. This in turn is susceptible to modification 831 by the local strength of the trade winds and even-more localised convection effects associated 832 with topography. For example, at SHV, several $100 \mathrm{~m}$ scale circular refractive phase anomalies 833 are evident as features that wax and wane with the diurnal cycle (Wadge, et al., 2016).

834

\section{Acknowledgements}

836 This work was supported by NERC grant NE/H019928/1 to GW with support from COMET. 837 TW is grateful for the NERC studentship NE/J500082/1. The COSMO-SKYMED radar data 838 were supplied by the Italian Space Agency under a CEOS scheme and we thank M. Pritchard 839 for his help in this regard. We acknowledge the radiosonde data came from the archive of the 840 Department of Atmospheric Sciences, University of Wyoming, the numerical model initial 841 condition data came from the ECMWF, Thomas Christopher at the Montserrat Volcano 842 Observatory provided a climatology dataset and Prof. Daniel Kirshbaum gave access to Fig. 8a. 843 Thanks, also, to Dr. Chris Holloway. The manuscript was greatly improved following 844 comments by four referees and the RSE editing team.

\section{References}

847 Alshawaf, F., Hinz, S, Mayer, M., Meyer, F.J. (2015) Construction accurate maps of 848 atmospheric water vapour by combining interferometric synthetic aperture radar and GNSS 849 observations. J. Geophys Res., 120/1391-1403, doi:10.1002/2014JD022419. 
850 Barclay, J., Johnstone, J.E., Matthews, A.J. (2006) Meteorological monitoring of an active 851 volcano: implications for eruption prediction. J. Volcanol., Geotherm. Res., 150, 339-358.

852 Bekaert, D.P.S. Hooper, A., Wright, T.J (2015) A spatially variable power law tropospheric 853 correction technique for InSAR data. J. Geophys. Res., 120, 1345-1356, doi: $854 \quad 10.1002 / 2014 J B 011558$.

855 Bekaert, D.P.S. Walters, R.J., Wright, T.J., Parker, D.J. (2015) Statistical comparison of InSAR 856 tropospheric correction techniques, Rem. Sensing Env., 170, 40-47.

857 Bengtsson, L. (2010) The global atmospheric water cycle. Env. Sci., Lett., 5, 025202.

858 Bennitt, G. and Jupp, A. (2012) Operational assimilation of GPS zenith total delay 859 observations into the Met Office Numerical Weather Prediction Models. Monthly Weather Rev., 140, 2706-2719.

864 Bevis, M., Businger, S., Herring, T.A., Anthes, R.A., Wadre, R.W. (1994), GPS meteorology: mapping zenith wet delays onto precipitable water. J. Appl. Meteor. 33(3), 379-386.

866 Boehm, J., Niell, A., Tregoning, P., Schuh, H., (2006) Global mapping function (GMF): a new 867 empirical mapping function based on numerical weather model data. Geophys. Res. Lett., 868 doi: 10.1029/2005GL025546.

869 Boehm, J. Heinkelmann, R. Schuh, H. (2007) Short Note: A global model of pressure and 870 temperature for geodetic applications. J. Geod., 81, 679-683.

871 Cécé, R., Bernard, D, D’Alexis, C., Dorville, J-F. (2014) Numerical simulations of island872 induced circulations and windward katabatic flow over the Guadeloupe Archipelago. 873 Monthly Weather Rev., 142, 850-867.

874 Costantini, M. (1998) A novel phase unwrapping method based on network programming. 875 IEEE, Trans. Geosci., Rem. Sens., 36/3, 813-821. 
876 D’Alexis, C., Abouna, A., Berthelot, H., Bernard, D. (2011) Characteristics of nocturnal 877 breezes in the Windward Islands in the southeastern Caribbean: structure and night-time 878 regimes. J. Caribbean Acad. Sci., 5(2).

879 Davison, J.L., Rauber, R.M., Di Girolamo, L., LeMone, M.A. (2013) A revised conceptual 880 model of the tropical marine boundary layer, Part I: statistical characterization of the 881 variability inherent in the wintertime trade wind regime over the western tropical Atlantic. 882 J. Atmos. Sci., 70, 3005-324.

883 Ebmeier, S.K. and co-authors (2018) Synthesis of global satellite observations of magmatic and 884 magmatic domains. J. App. Volcanol., 7:2, doi: 10.1186/513617-018-0071-3.

Elliott, J.R., Biggs, J., Parsons, B. Wright, T.J. (2008) InSAR slip rate determination on the 887 Altyn Tagh Fault, northern Tibet, in the presence of topographically correlated

894 Fattahi, H., Amelung, F. (2014) Insar uncertainty due to orbital errors. Geophys. J. Int., 199/1, 895 $549-560$.

896 Fattahi, H., Simons, M., Agram, P., (2017) InSAR time-series estimation of the ionospheric 897 phase delay: an extension of the split range-spectrum technique., IEEE, Trans., Geosci, Rem, $898 \quad$ Sens., 55/10, doi: 10.1109/TGRS.2017.2718566.

899 Hanssen, R.F. (2001) Radar Interfeometry. Data interpretation and error analysis. Kluwer 900 Academic Publishers, Dordrecht, 308 pp.

901 Feng, J., Zhen, W., Wu, Z. (2017) Ionospheric effects on repeat-pass SAR interferometry. Adv. 902 Space Res., 60, 1504-1515, doi: 10.1016/j.asr.2017.06.019. 
903 Herring, T.A., King, R.W., Floyd, M.A. and McClusky, S.C. (2010a) GAMIT Reference

904 Manual, GPS Analysis at MIT. Department of Earth, Atmospheric and Planetary Sciences, 905 Massachusstst Institute of Technology, Cambridge, USA.

906 Herring, T. A., Floyd, M.A., King, R. W., and McClusky, S. C. (2010b) GLOBK reference 907 manual, Global Kalman filter VLBI and GPS analysis program. Department of Earth, 908 Atmospheric, and Planetary Sciences, Massachusetts Institute of Technology, Cambridge. 909 USA.

910 Hofmann-Wellenhof, B., Lichtenegger, H., Collins, J. (1995) Global Positioning System, 911 Theory and Practice, $3^{\text {rd }}$ edition, Springer-Verlag, Wien.

912 Goldstein, R.M. and Werner, C.L. (1998) Radar interferogram filtering for geophysical 913 applications. Geophys., Res., Lett., 25/21, 4035-4038,10.1029/95GL900033.

914 Gonzalez, A., Exposito, F.I., Perez, J.C., Diaz, J.P., Taima, D. (2013) Verification of 915 precipitable water vapour in high resolution WRF simulations over a mountainous 916 archipelago. Q. J. R. Meteorol., Soc., 139:2119-2133.

917 Heleno, S.I.N., Frischknecht, C., d’Oreye, N., Lima, J.N.P., Faria, B., Waff, R., Kervyn, F. 918 (2010) Seasonal tropospheric influence on SAR interferograms near the ITCZ- the case of 919 Fogo Volcano and Mount Cameroon. J. African Earth Sci., 58/5 833-856. 10.1016/j920 jafreasci, 2009-07-013.

921 Li, Z., Fielding, E., Cross, P., Muller, J-P., (2005) InSAR atmospheric correction - GPS 922 topography-dependent turbulence model (GTTM). J. Geophys. Res., 110, B02404, doi: $923 \quad 10.1029 / 2005 J B 003711$.

924 Li, Z., Cao, Y., Wei, J., Duan, M., Wu, L., Hou, J., Zhu, J., (2019) Time series InSAR ground 925 deformation monitoring: atmospheric delay modelling and estimating. Earth Sci. Rev., 192, $926 \quad 258-284$. 
Jolivet, R., Grandin, R., Lasserre, C., Doin, M-P., Peltzer, G., (2011) Systematic InSAR tropospheric phase delay corrections from global meteorological reanalysis data. Geophys., Res., Lett., 38, L17311 doi: 10.1029/2011GL 048757.

Jolivet, R., Agram, P.S., Lin, N.Y., Simons, M., Doin, M.P., Peltzer, G., Li, Z. (2014) Improving InSAR geodesy using global atmospheric models. J. Geophys., Res., 119(3), 2324-2341.

Kirshbaum, D.J., Durran, D.R. (2004) Factors governing cellular convection in orographic precipitation. J. Atmos. Sci., 61, 682-698.

Kirshbaum, D.J., Smith, R.B. (2009) Orographic precipitation in the tropics: large-eddy simulations and theory. J. Atmos. Sci., 66, 2559-2578.

Kirshbaum, D.J., Fairman Jr., J.G. (2015) Cloud trails past the Lesser Antilles. Monthly Weather Rev., April 2015, 995-1017.

Kirshbaum, D. J., (2017) On upstream blocking over heated mountain ridges. Q. J. R. Meteorol. Soc., 143: 53-68.

Laderach, A., Raible, C.C., (2013) Lower troposphere humidity: climatology, trends and the relation to the ITCZ. Tellus A, 65, 20413, doi10.3402/tellus v.6510.20413.

Lager K., Schindelegger M., Bohm J., Krasna H., Nilsson T (2013) GPT2: Empirical slant delay model for radio space geodetic techniques. Geophys. Res. Lett. 40,6, 1069-1073.

Lu, Z., Dzurisin, D. (2014) InSAR imaging of Aleutian Volcanoes, Springer, New York, pp.390.

McVicar, T.R. and Korner, C. (2013) On the use of elevation, altitude and height in the ecological and climatological literature. Oecologia, 171, 335-357. Doi: 10.1007/S00442 012-2416-7.

Massonnet, D. and Feigl, K. (1998) Radar interferometry and its application to changes in the Earth's surface. Rev. Geophys., 36, 441-500. 
951 Matthews, A.J., Barclay, J., Carn, S., Thompson, G., Alexander, J., Herd, R.A., Williams, C. 952 (2002) Rainfall-induced volcanic activity on Montserrat. Geophys. Res. Lett., 29, (130), 1644, doi:10.1029/2002GL014863.

954 Martinez, C., Goddard, L., Kushnir, Y., Ting, M. (2019) Seasonal climatology and dynamical 955 mechanisms of rainfall in the Caribbean. Climate Dynamics, doi: 10.1007/s00382-019$956 \quad 04616-4$.

957 Minder, J.R., Smith, R.B., Nugent A.D. (2013) The dynamics of ascent-forced orographic 958 convection in the tropics: results from Dominica. J. Atmos. Sci., 70, 4067-4088.

959 Munoz, E., Busalacchi, A.J., Nigam, S., Ruiz-Barradas, A. (2008) Winter and summer structure 960 of the Caribbean Low-Level Jet., J. Climate, 21/1260-1276.

961 Nugent, A.D., Smith, R.B., Minder, J.R. (2014) Wind speed control of tropical orographic 962 convection. J. Atmos. Sci., 71, 2695-2712.

963 Odbert, H.M., Ryan, G.A., Mattioli, G.S., Hautmann, S., Gottsmann, J., Fournier, M., Herd, 964 R.A., (2014) Volcanic geodesy at Soufriere Hills Volcano, Montserrat: a review. From: 965 Wadge, G., Robertson, R.E.A., Voight, B. (eds.) The eruption of Soufriere Hills Volcano, 966 Montserrat from 2000 to 2010. Geol. Soc. London, Memoirs, 39, 195-217. 967 doi/101144/M39.11.

968 Pausato, F.S.R., Camargo, S.J. (2019) Tropical cyclone activity affected by volcanically 969 induced ITCZ shifts. PNAS, 116/16, doi:10.1073/pnas.1900777116.

970 Poulidis, A.P., Renfrew, I.A., Matthews, A.J. (2016) Thermally induced convective circulation 971 and precipitation over an isolated volcano. J. Atmos. Sci., April 2016. Doi: 10.1175/JAS-D$972 \quad 14-0327.1$.

973 Pritchard, M. E. and co-authors (2018) Towards coordinated regional multi-satellite InSAR 974 volcano observations: results from Latin America pilot project. J. App. Volcanol., 7:5 975 doi/10.1186/513617-018-00746. 
976 Richter, I., Xie, S-P., Morioka, Y., Doi, T., Taguchi, B., Behera, S., (2017). Phase locking of 977 equatorial Atlantic variability through seasonal migration of the ITCZ. Clim. Dyn., 48, 3615$978 \quad 3289$.

979 Siebsma, A.P., Bretherton, C.S., Brown, A., Chlond, A., Cuxart, J., Duynkerke, P.G., Jiang, H., 980 Khairoutdinov, M., Lewellen, D., Moeng, C-H, Sanchez, E., Stevens, B., Stevens, D.E. 981 (2003) A large eddy simulation inter-comparison study of the shallow cumulus convection. 982 J. Atmos. Sci., 60/10, 1201-1219.

983 Schneider, T., Bischoff, T., Haug, G.H. (2014) Migrations and dynamics of the Intertropical 984 Convergence Zone. Nature, Review.513, 45-53.

985 Skamarok, W.C., and co-authors (2008) A description of the Advanced Research WRF version 986 3. NCAR Tech. Note NCAR/TN-475+STR, 113 pp.

Smith, R.B., Gleason, A.C., Gluhosky, P.A., Grubisic, V. (1997) The wake of St Vincent. J. 988 Atmos. Sci., 54, 606-623.

989 Smith, R.B., Minder, J.R., Nugent, A.D., Storelvmo, T., Kirshbaum, D.J., Warren, R., Lareau, 990 N., Palany, P., Arlangton, J., French, J. (2012) Orographic precipitation in the tropics. Bull. 991 Am. Meteor. Soc., October, 2012,1567-1579.

992 Spaans, K., Hooper, A., (2016) InSAR processing for volcano monitoring and other near real993 time applications. J. Geophys. Res.: Solid Earth, 121,2947-2960. 10.1002/2015JB012752.

994 Stevens, B., (2006) Bulk boundary-layer concepts for simplified models of tropical dynamics. 995 Theor. Comput. Fluid Dyn. 20, 279-304.

996 Stinton A., Bass V., Christopher T., Edgecombe N., Fergus M., Pascal K., Smith P., Stewart 997 R., Syers R., Williams C. (2016) MVO Scientific Report for Volcanic Activity between 1 998 October 2015 and 30 April 2016, Montserrat Volcano Observatory Open File Report OFR $999 \quad 16-02$. 
1000 $1001 \quad$ pp.

1002

1003

1004

1005

1006

1007

1008

1009

1010

1011

1012

1013

1014

1015

1016

1017

1018

1019

1020

1021

1022

1023

1024

Stull, R.B., (1988) An introduction to boundary layer meteorology. Springer, Heidelberg, 666

Taylor, M.A., Alfaro, E.J. (2005) Climate of Central America and the Caribbean. In: Oliver J.E., Encyclopedia of World Climatology. Encyclopedia of Earth Sciences series. Springer, Dordrecht.

Wadge, G., Webley, P.W., James, I.N., Bingley, R., Dodson, A., Waugh, S., Veneboer, T., Puglisi, G., Mattia, M., Baker, D., Edwards, S.C., Edwards, S.J., Clarke, P.J. (2002) Atmospheric models, GPS and InSAR measurements of the tropospheric water vapour field over Mount Etna. Geophys. Res. Lett., 29/19, 11-1 - 11-4, doi: 10.1029/2002GL015159.

Wadge, G., Mattioli, G.S., Herd, R.A. (2006) Ground deformation at Soufriere Hills Volcano, Montserrat during 1998-2000 measured by radar interferometry and GPS. J. Volcanol. Geotherm. Res., 152/1-2, j.jvolgeores,205.11.007.

Wadge, G., Zhu, M., Holley, R.J., James, I.N., Clark, P.A., Wang, C., Woodage, M.J. (2010) Correction of atmospheric delay effects in radar interferometry using a nested mesoscale atmospheric model. J. App. Geophys., 72, 141-149.

Wadge, G., Voight, B., Sparks, R.S.J., Cole, P.D., Loughlin, S.C., Roberston, R.E.A., An overview of the eruption of Soufriere Hills Volcano from 2000 to 2010. From: Wadge, G., Robertson, R.E.A., Voight, B. (eds.) The eruption of Soufriere Hills Volcano, Montserrat from 2000 to 2010. Geol. Soc. London, Memoirs, 39, 1-39. doi/101144/M39.11.

Wadge, G., Costa, A., Pascal., K., Werner, C., Webb, T. (2016) The variability of refractivity in the atmospheric boundary layer of a tropical island measured by ground-based interferometric radar. Bound. Layer Meteorol. 161/2, 309-333. doi:10.1007/s10546-0160168-3.

Waliser, D. E., Gautier, C. (1993) A satellite-derived climatology of the ITCZ. J. Climate, 6, $2162-2174$ 
1025 Wang, C-C., Kirshbaum., D.J. (2015) Thermally forced convection over a mountainous tropical 1026 island. J. Atmos. Sci., 72, 2484-2506.

1027 Webb, T.L. (2015) High resolution atmospheric modelling of a tropical island for space 1028 geodesy. Ph.D. thesis, University of Reading.

1029 Zebker H.A., Villasenor, J. (1992) Decorrelation in interferometric maps. IEEE Trans. Geosci., 1030 Rem. Sensing, 30/5, 950-959. 
1031 


\section{Method to simulate the ZWD field from GPS-derived values}

1035

1036

1037 In practice, we use a 4-step method to separate and interpolate the topographic and dynamic 1038 components of the zenith wet delay field before recombining them:

1040 1. Normalize the ZWD values to sea-level equivalence for all 14 sites using the ZWD lapse 1041 rate. Assume that the remaining anomalies are due to horizontal differences in the water $1042 \quad$ vapour field.

1044 2. Interpolate the 14 (or less, depending on receiver availability) values of lateral delay to a 25 1045 m grid using kriging to create field $\mathrm{H}$.

1046

1047 3. Multiply the elevation values at each $25 \mathrm{~m}$ posting of the DEM (equivalent to field $\mathrm{H}$ ) with 1048 the ZWD lapse rate. This gives the vertical variability due to topography, field V.

1050 4. Add fields $\mathrm{H}$ (horizontal component) and V (vertical component). 1051 

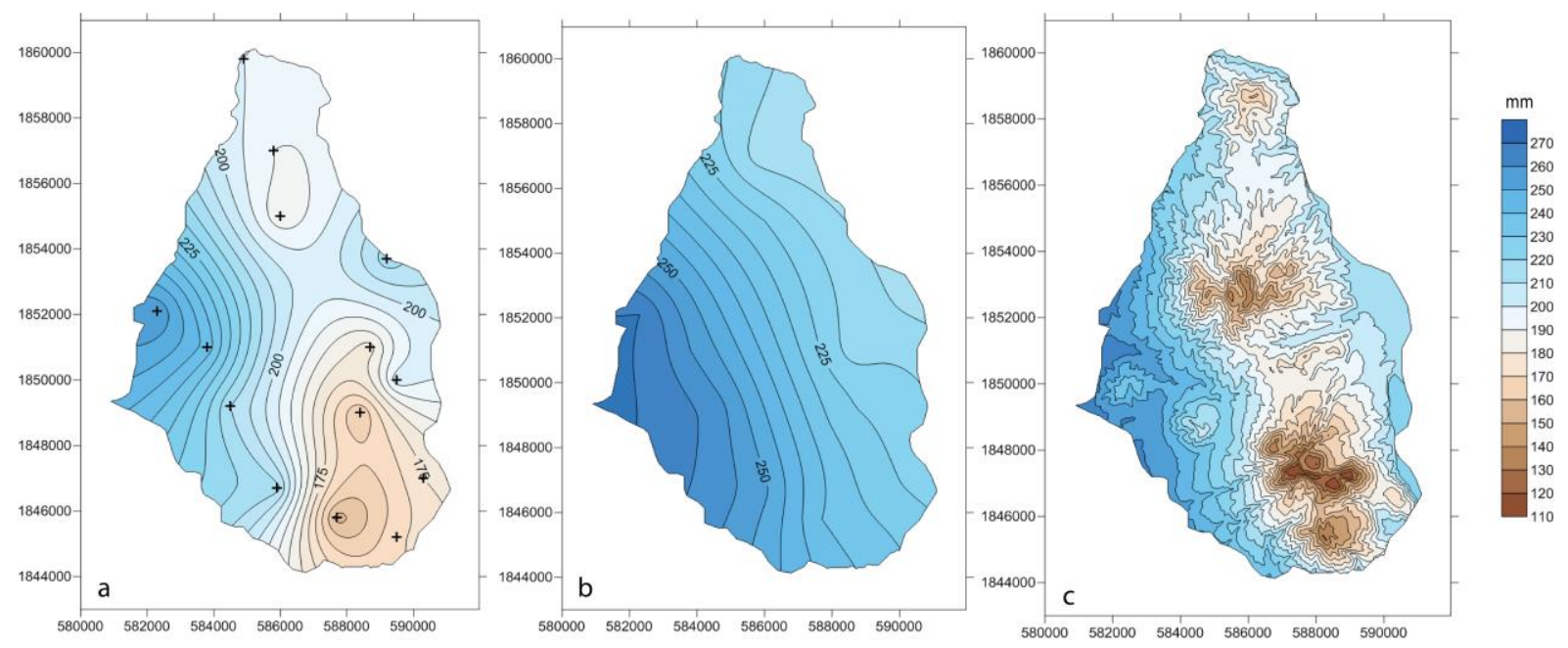

Fig. S1 ZWD fields (mm) at 17:30 (local time) on $3^{\text {rd }}$ August 2013. (a) Field interpolated from the 14 GPS observation sites (black crosses). (b) Horizontal gradient field after normalising values in (a) to sea level. (c) Combined horizontal $(b)$ and vertical fields interpolated using the water vapour lapse rate $(0.14 \mathrm{~mm} / \mathrm{m}) \mathrm{multiplied}$ by the elevations of each cell of a 25 m horizontal resolution DEM.

1059 Figure S1 shows the resulting ZWD field for the 17:30, $3^{\text {rd }}$ August 2013. Low values of ZWD are concentrated along the central, mountainous, spine of the island (Fig. S1a). But the lack of

1061 observations in the central part of the island produces higher than expected values in the 1062 interpolated field. The horizontal component of the field shows a clear ENE gradient of about $106350 \mathrm{~mm}$ of delay across the island (Fig. S1b). This gradient is the same orientation as that 1064 observed by MODIS and WMM (Fig. 4), and is of similar amplitude compared to the lee wave anomalies from WMM of $\sim 70 \mathrm{~mm}$. The full, $25 \mathrm{~m}$ horizontal resolution ZWD field is shown in 1066 Fig. S1c. 